\title{
Activity of Ventral Medial Thalamic Neurons during Absence Seizures and Modulation of Cortical Paroxysms by the Nigrothalamic Pathway
}

\author{
Jeanne Tamar Paz, ${ }^{1,2}$ Mario Chavez, ${ }^{3}$ Sandrine Saillet, ${ }^{1,2,4}$ Jean-Michel Deniau, ${ }^{1,2}$ and Stéphane Charpier ${ }^{1,2}$ \\ ${ }^{1}$ Institut National de la Santé et de la Recherche Médicale (INSERM), Unité 667, Collège de France, F-75231 Paris, France, ${ }^{2}$ Université Pierre et Marie Curie, \\ F-75005 Paris, France, ${ }^{3}$ Centre National de la Recherche Scientifique Unité Propre de Recherche 640, Laboratoire de Neurosciences Cognitives et Imagerie \\ Cérébrale, Hôpital de la Pitié Salpêtrière, and ${ }^{4}$ INSERM, Unité 739, Hôpital de la Pitié Salpêtrière, F-75651 Paris, France
}

\begin{abstract}
Absence seizures are characterized by bilaterally synchronous spike-and-wave discharges (SWDs) in the electroencephalogram, which reflect abnormal oscillations in corticothalamic networks. Although it was suggested that basal ganglia could modulate, via their feedback circuits to the cerebral cortex, the occurrence of SWDs, the cellular and network mechanisms underlying such a subcortical control of absence seizures remain unknown. The GABAergic projections from substantia nigra pars reticulata (SNR) to thalamocortical neurons of the ventral medial (VM) thalamic nucleus provide a potent network for the control of absence seizures by basal ganglia. The present in vivo study provides the first description of the activity of VM thalamic neurons during seizures in the genetic absence epilepsy rats from Strasbourg, a well established model of absence epilepsy. Cortical paroxysms were accompanied in VM thalamic neurons by rhythmic bursts of action potentials. Pharmacological blockade of excitatory inputs of nigrothalamic neurons led to a transient interruption of SWDs, correlated with a change in the activity of thalamic cells, which was increased in frequency and converted into a sustained arrhythmic firing pattern. Simultaneously, cortical neurons exhibited a decrease in their firing rate that was associated with an increase in membrane polarization and a decrease in input resistance. These new findings demonstrate that an inhibition of SNR neurons changes the activity of their thalamic targets, which in turn could affect cortical neurons excitability and, consequently, the generation of cortical epileptic discharges. Thus, the nigro-thalamo-cortical pathway may provide an on-line system control of absence seizures.
\end{abstract}

Key words: ventral medial thalamic nucleus; absence epilepsy; basal ganglia; in vivo; substantia nigra pars reticulate; GAERS

\section{Introduction}

Absence epilepsy is a generalized, nonconvulsive epilepsy of multifactorial genetic origin (Panayiotopoulos, 1997; Crunelli and Leresche, 2002). Absence seizures consist of a brief and sudden impairment of consciousness concomitant with bilateral synchronized spike-and-wave discharges (SWDs) in the electroencephalogram (EEG) over wide cortical areas (Panayiotopoulos, 1997). Electrophysiological recordings in patients (Williams, 1953) and various animal models of absence epilepsy (for review, see Danober et al., 1998; Timofeev and Steriade, 2004) revealed that SWDs result from abnormal oscillations in thalamocortical loops. Studies in genetic absence epilepsy rats from Strasbourg (GAERS), a well established model of absence epilepsy (Marescaux et al., 1992; Danober et al., 1998), suggest that basal ganglia provide a subcortical system controlling absence seizures via a

Received 0ct. 27, 2006; revised Nov. 28, 2006; accepted Dec. 17, 2006.

This work was supported by the Ministère Français de la Recherche and the Agence Nationale de la Recherche (ANR 2006). We are grateful to Drs. S. Mahon, R. Miles, and P. O. Polack for thoughtful discussion and critical reading of this manuscript. We also thank Dr. N. Maurice for assistance with the pharmacological experiments and A.-M. Godeheu for assistance with the histological processing.

Correspondence should be addressed to Jeanne Tamar Paz, Institut National de la Santé et de la Recherche Médicale, Unité667, Collège de France, F-75231 Paris, France. E-mail: jeanne.paz@college-de-france.fr. DOI:10.1523/JNEUROSCI.4677-06.2007

Copyright @ 2007 Society for Neuroscience $\quad$ 0270-6474/07/270929-13\$15.00/0 modulation of activity of the substantia nigra pars reticulata (SNR), the main basal ganglia output structure (for review, see Danober et al., 1998; Deransart et al., 1998; Deransart and Depaulis, 2002). For instance, pharmacological activation of GABAergic striatonigral neurons, as well as application of $\mathrm{GABA}_{\mathrm{A}}$ agonists within the SNR, suppresses absence seizures, whereas an aggravation of cortical paroxysms is obtained after application of $\mathrm{GABA}_{\mathrm{A}}$ antagonists in the SNR (Danober et al., 1998; Deransart et al., 1998). Moreover, recent in vivo electrophysiological studies in GAERS demonstrated that SWDs propagate in basal ganglia circuits with a severe functional imbalance between the cortico-striato-nigral and cortico-subthalamonigral pathways (for review, see Paz et al., 2005b) (Fig. 1). Specifically, propagation of epileptic discharges in corticostriatal axons produces a powerful feedforward inhibition of GABAergic striatal output neurons (Slaght et al., 2004; Paz et al., 2005b), whereas paroxysmal discharges in the corticosubthalamic pathway generate synchronized bursting activity in glutamatergic subthalamonigral neurons (Paz et al., 2005a,b) (Fig. 1). Such an increase in subthalamo-nigral activity, together with the silencing of striatonigral neurons, are consistent with the rhythmic bursting observed in SNR cells during ictal activity in freely moving GAERS (Deransart et al., 2003). Together, these findings suggest that changes in the firing of nigral neurons could modulate "on-line" 


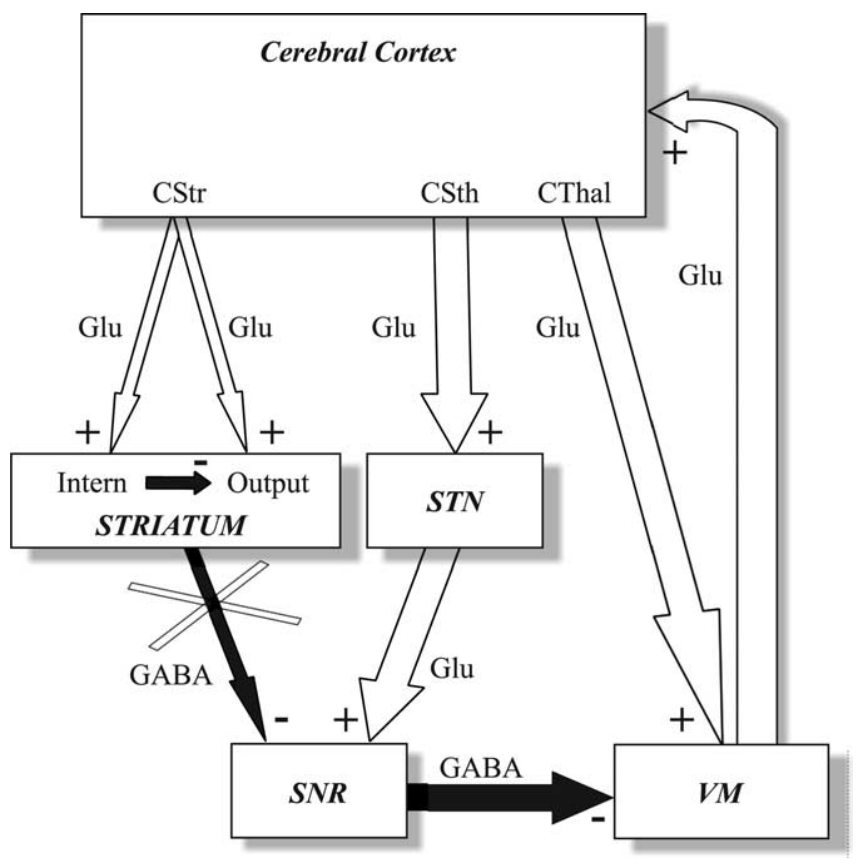

Figure 1. Simplified diagram of the circuits connecting cerebral cortex and basal ganglia and propagation of cortical paroxysms during absence seizures. Cortical SWDs propagate to the striatum and the subthalamic nucleus (STN) with an imbalance (relative thickness of corresponding arrows) between the activity of corticostriatal (CStr) and corticosubthalamic (CSth) neurons. Whereas striatal output neurons (Output) are silenced (white cross) via a feedforward inhibition, because of the activation of GABAergic striatal interneurons (Intern), subthalamonigral neurons produce a rhythmic excitation of SNR neurons. In turn, nigral neurons inhibit VM thalamocortical neurons, which also receive excitatory inputs from corticothalamic (CThal) neurons. The white and black arrows represent glutamatergic (Glu) excitatory (+) and GABAergic (GABA) inhibitory (-) projections, respectively. See Introduction for details.

the occurrence of absence seizures. However, the cellular and network mechanisms by which the SNR could affect the cortical excitability and regulate the emergence of SWDs remain unknown.

The GABAergic nigrothalamic projections to the ventral medial nucleus (VM) of the thalamus (Di Chiara et al., 1979; Yoshida and Omata, 1979; Kilpatrick et al., 1980; Chevalier and Deniau, 1982; Ueki, 1983) represent a major efferent system of basal ganglia through which electrical signals propagated in basal ganglia networks are conveyed to the neocortex (Herkenham, 1979, 1980; Glenn et al., 1982; Moran et al., 1982) (Fig. 1). Thus, the nigro-thalamo-cortical pathway provides a potent feedback circuit that could control absence seizures. In the present study, we first characterized, in vivo in the GAERS, the firing pattern and intracellular events of VM thalamic neurons during SWDs. We further examined the mechanisms of control of cortical seizures by the nigrothalamic pathway by determining the impact of a transient blockade of subthalamo-nigral glutamatergic transmission on the firing of VM thalamocortical cells and its repercussion on cortical neurons excitability.

\section{Materials and Methods}

All experiments were performed in accordance with local ethical committee and European Union guidelines (Directive 86/609/EEC) and every precaution was taken to minimize stress and the number of animals used in each series of experiments.

Animal preparation. Experiments were performed in vivo from 28 GAERS (20 females and 8 males; $3-10$ months of age; $170-340 \mathrm{~g}$ ) and 7 nonepileptic Wistar rats (5 females and 2 males; $3-5$ months of age; $200-280 \mathrm{~g}$ ). Animals were initially anesthetized with sodium pentobar- bital (40 mg/kg, i.p.; Sanofi, Libourne, France) and ketamine (100 mg/kg, i.m.; Imalgène, Rhone Mérieux, France). A cannula was inserted into the trachea and the animal was placed in a stereotaxic frame. Wounds and pressure points were repeatedly (every $2 \mathrm{~h}$ ) infiltrated with lignocaine (2\%). Once the surgical procedures had been completed (see below), ear bars were removed and the head was held via a metallic rod cemented to the skull. Rats were subsequently maintained in a narcotized and sedated state by injections of fentanyl ( $4 \mu \mathrm{g} / \mathrm{kg}$, i.p.; Janssen-Cilag, Issy-LesMoulineaux, France) repeated every 20-30 min (Simons and Carvell, 1989; Pinault et al., 1998; Charpier et al., 1999; Slaght et al., 2002a, 2004; Bruno et al., 2003; Paz et al., 2005a). To obtain long-lasting stable intracellular recordings, rats were immobilized with gallamine triethiodide (40 mg, i.m., every 2 h; Specia, Paris, France) and artificially ventilated. The degree of anesthesia was assessed by continuously monitoring the EEG and heart rate, and additional doses of fentanyl were administered at the slightest change toward a waking pattern (i.e., an increase in the frequency and reduction in amplitude of EEG waves and/or an increase in the heart rate). Body temperature was maintained $\left(36.5-37.5^{\circ} \mathrm{C}\right)$ with a homeothermic blanket. At the end of the experiments, animals received an overdose of sodium pentobarbital ( $200 \mathrm{mg} / \mathrm{kg}$, i.p.).

Electrophysiological recordings. EEG recordings were obtained with a low-impedance $(\approx 60 \mathrm{~K} \Omega)$ silver electrode placed on the dura above the orofacial motor cortex $(12.5 \mathrm{~mm}$ anterior to the interaural line, 3.3-4 mm lateral to the midline) (Hall and Lindholm, 1974; Neafsey et al., 1986; Paxinos and Watson, 1986) and the somatosensory cortex (6.7 mm anterior to the interaural line, $4 \mathrm{~mm}$ lateral to the midline) (Paxinos and Watson, 1986). The reference electrode was placed in the muscle on the opposite side of the head.

Intracellular recordings were performed using glass micropipettes filled with $2 \mathrm{M}$ potassium acetate $(40-70 \mathrm{M} \Omega)$. Measurements of apparent membrane input resistance and time constant were based on the linear electrical cable theory applied to an idealized isopotential neuron (Rall, 1969). The voltage-current $(V-I)$ relationship was measured from variations of the membrane potential in response to intracellular injections of hyperpolarizing current pulses $(-0.2$ to $-1.2 \mathrm{nA} ; 200 \mathrm{~ms}$ duration; every $1.55 \mathrm{~s} ; n \geq 6$ ) applied through the recording electrode. Apparent input resistance was measured from the mean $(n \geq 6)$ membrane potential change at the end of hyperpolarizing current pulses of low intensity ( $-0.4 \mathrm{nA} ; 200 \mathrm{~ms}$ duration; every $1.55 \mathrm{~s})$ applied through the recording electrode or by measurement of the slope of the linear portion of the $V-I$ curve (see Fig. $4 A 2, B 2$ ). The values of membrane potential were corrected according to the potential recorded extracellularly immediately after termination of the intracellular recording. The membrane time constant, calculated from $-0.4 \mathrm{nA}$ current pulses, was the time taken for the membrane potential to reach $63 \%$ of its final value. The mean membrane potential was calculated during interictal activity from recording periods of $25 \mathrm{~s}$.

For single-unit extracellular recordings and juxtacellular labeling (see below), glass electrodes were filled with $0.5 \mathrm{M} \mathrm{NaCl}$ and $1.7 \%$ neurobiotin (10-20 M $\Omega$; Vector Laboratories, Burlingame, CA).

Cortical cells, located in the orofacial motor cortex, were recorded within $300 \mu \mathrm{m}$ of the EEG electrode at the following coordinates: 12.5 $\mathrm{mm}$ anterior to the interaural line, 3-4 $\mathrm{mm}$ lateral to the midline, and 0.93-2.72 mm below the cortical surface, indicating a somatic localization in the layers V and VI (Zilles, 1985).

Intracellular, single-unit and multiunit extracellular recordings in the VM thalamic nucleus were obtained from the region projecting to the orofacial motor cortex (Herkenham, 1979, 1980; Glenn et al., 1982; Deniau and Chevalier, 1985) and receiving inputs from the orofacial region of SNR (Deniau and Chevalier, 1992). The corresponding stereotaxic coordinates were $5.9-6.7 \mathrm{~mm}$ anterior to the interaural line, $1.3-1.8 \mathrm{~mm}$ lateral to the midline, and $6.40-7.14 \mathrm{~mm}$ below the cortical surface. Intracellular recordings from ventral lateral (VL) thalamic neurons were obtained at the corresponding coordinates, 5.9-6.7 $\mathrm{mm}$ anterior to the interaural line, $1.4-1.8 \mathrm{~mm}$ lateral to the midline, and $5.50-6.30 \mathrm{~mm}$ below the cortical surface (Paxinos and Watson, 1986).

Extracellular recordings from SNR neurons were obtained at the following coordinates: $3.4-3.7 \mathrm{~mm}$ anterior to the interaural line, $2.4-3.2$ $\mathrm{mm}$ lateral to the midline, and $7.05-8.10 \mathrm{~mm}$ below the cortical surface. 
In all experiments, intracellular or single-unit and multiunit extracellular recordings were simultaneously performed with the corresponding ipsilateral EEG of orofacial motor cortex.

Pharmacology. Pharmacological blockade of glutamatergic transmission in the SNR was obtained after local injection of kynurenate (KYNU) (100 nl; 75 mm; Sigma, Fallavier, France), a nonselective NMDA and AMPA receptors antagonist (Stone, 1993), via a glass micropipette (tip diameter, $40-50 \mu \mathrm{m}$ ) fitted to a $1 \mu \mathrm{l}$ Hamilton syringe (Chevalier et al., 1985). Kynurenate was dissolved in $\mathrm{NaCl}(0.9 \%)$ and all solutions were adjusted to $\mathrm{pH}$ 7.4. Kynurenate was injected within the SNR at the following stereotaxic coordinates: $3.2 \mathrm{~mm}$ anterior to the interaural line, 2.2-2.4 $\mathrm{mm}$ lateral to the midline, and 7.7-8 $\mathrm{mm}$ below the cortical surface. When SNR neurons were simultaneously recorded ( $n=5$ experiments), the injection micropipette was positioned obliquely within the SNR and its tip was sufficiently distant $(\sim 0.20 \mathrm{~mm})$ from the vertical recording electrode to avoid any mechanical interference between the injection and the electrophysiological recording. Kynurenate injection, at a volume of $100 \mathrm{nl}$ that diffuses for distances $<0.2-0.3 \mathrm{~mm}$ (Myers, 1971; Robledo and Feger, 1990), was thus restricted to the SNR without diffusion in neighboring structures. For each animal, the exact location of injection sites in SNR was determined on histological sections using the atlas of Paxinos and Watson (1986).

Morphological identification. Extracellularly recorded neurons were labeled by juxtacellular injection of Neurobiotin (Pinault, 1996; Mailly et al., 2003). Briefly, positive current pulses (1-8 nA; $200 \mathrm{~ms}$ ) were applied at a frequency of $2.5 \mathrm{~Hz}$ through the bridge circuit of the amplifier. The current was slowly increased while the electrode was advanced toward the neuron in $1 \mu \mathrm{m}$ steps (LSS-1000 Inchworm Motor Positioning System; Burleigh Instruments, Fishers, NY) until the cell discharge was driven by the injected current. Current pulses were applied for a 10-30 min period to obtain a reliable labeling of neuronal processes. For intracellular recordings, depolarizing current pulses (0.2-1 nA; 100-200 ms) were applied at a frequency of $2.5 \mathrm{~Hz}$ at the end of the recording period. The histochemical methods used to reveal the morphology of neurobiotin-filled neurons have been described in detail previously (Slaght et al., 2002a). The position of labeled neurons within the structures was confirmed using the atlas of Paxinos and Watson (1986).

Data acquisition and analysis. Intracellular recordings were obtained under current-clamp conditions using the active bridge mode of an Axoclamp 2B amplifier (Molecular Devices, Union City, CA). Data were stored on-line on a DRA 800 digital tape recorder (Biologic, Claix, France) and then digitized with a sampling rate of $20 \mathrm{kHz}$ (intracellular signals), $10 \mathrm{kHz}$ (extracellular signals), or $300 \mathrm{~Hz}$ (EEG) for off-line analysis. To perform spectral analysis of EEG potentials, fast Fourier transforms were applied using Spike 2 (CED Software; Cambridge Electronic Design, Cambridge, UK). Cross-correlograms of the firing between two simultaneously recorded units were obtained by first encoding the position of the peak of the action potentials into separate channels using the memory buffer function of Spike 2, and the event correlation function was then used to produce the cross-correlogram. The amplitude of action potentials was calculated as the potential difference between their voltage threshold, measured as the membrane potential at which the $d V / d t$ exceeded $10 \mathrm{~V} \cdot \mathrm{s}^{-1}$ (Mahon et al., 2003), and their peak. Numerical values are given as means \pm SEM unless stated otherwise. Statistical significance was assessed by performing appropriate statistical tests, Student's paired $t$ test, one-way ANOVA, or Mann-Whitney test. In some measurements, the normality of distributions was tested using the Kolmogorov-Smirnov test and a Gaussian-Laplace fit was performed. Statistical analysis and curve fitting were performed with Origin 7.0 (Microcal Software, Northampton, MA) and SigmaStat 3.0 (SPSS, Chicago, IL).

To quantify the degree of statistical association and the time delay between EEG waves and intracellular activity of VM thalamic neurons, the nonlinear correlation coefficient $h^{2}$ was calculated between these signals as a function of a time shift $(\tau)$ (Lopes da Silva et al., 1989; Slaght et al., 2004). In contrast with classical methods, such as cross-correlation or coherence, which are only sensitive to linear relationships, this nonlinear index can reveal signal interdependencies under more general conditions (Meeren et al., 2002).
To quantify the dependence of a signal $Y$ on a signal $X$, an estimator of the nonlinear correlation index $\left(h^{2}\right)$ was computed as follows:

$$
h^{2}(x \rightarrow y)=\frac{\sum_{i=1}^{N}\left(y_{i}-\langle y\rangle\right)^{2}-\sum_{i=1}^{N}\left(y_{i}-g\left(x_{i}\right)\right)^{2}}{\sum_{i=1}^{N}\left(y_{i}-\langle y\rangle\right)^{2}},
$$

where $g\left(x_{i}\right)$ denotes a piecewise linear regression curve, used to predict the signal $Y$ at any value of $X$, and $\langle y\rangle$ denotes the average of the time series $y_{i}$ over $N$ samples. Statistically, this nonlinear correlation index quantifies the reduction of variance that can be obtained by predicting the $Y$ values on the basis of the regression curve. The nonlinear index ranges between 0 , when both signals are independent, and 1 , for a perfect dependence. Theoretical and practical aspects of this method have been described in detail previously (Lopes da Silva et al., 1989).

In the present study, the degree of association between EEG and intracellular signals and the corresponding time delays during seizures were obtained by computing $h^{2}$ as a function of a time shift $(\tau)$ between the signals $y$ and $x$. The shift for which the maximum of $h^{2}(\tau)$ was reached provided an estimate of the time delay between the activities (Lopes da Silva et al., 1989; Meeren et al., 2002). Because epileptic activities are not stationary in time, correlation indices were computed for sliding short epochs of $2 \mathrm{~s}$ with $98 \%(\approx 1.96 \mathrm{~s})$ of temporal overlap.

\section{Results}

\section{Properties of cortical SWDs}

The temporal properties of SWDs recorded by the surface EEG electrode, as well as the shape of individual spike-wave complexes, were similar to those previously described under analogous experimental conditions (Pinault et al., 1998; Charpier et al., 1999; Slaght et al., 2002a,b, 2004; Pinault, 2003; Paz et al., 2005a) and in freely moving GAERS (Marescaux et al., 1992; Deransart et al., 2003). Specifically, SWDs ( $n=1777$ from 28 GAERS) recorded in the present study had a mean duration of $4.7 \pm 0.4 \mathrm{~s}$ (from 0.9 to $140 \mathrm{~s}$ ) and recurred once every $52.5 \pm 10.6 \mathrm{~s}$. The intra-SWD frequency, revealed by spectral analysis of the EEG signal, ranged from 7 to $9.5 \mathrm{~Hz}$.

\section{Extracellular activity of VM thalamic neurons}

\section{Single-unit recordings}

We first examined the spontaneous activity of VM thalamic neurons in GAERS in extracellular recordings of single units ( $n=30$ cells from six rats). Recorded cells, which were morphologically identified by juxtacellular injection of Neurobiotin (see Materials and Methods), were located in the region of the VM thalamic nucleus (Figs. $2 A 1,3 D$, inset) related to the orofacial motor cortex (Herkenham, 1979, 1980; Glenn et al., 1982; Deniau and Chevalier, 1985). They exhibited the morphological characteristics of VM thalamic cells (Figs. 2A1, $3 D$ ), either a fusiform or polygonal soma, with a diameter of $\sim$ $25 \mu \mathrm{m}$, and widespread dendritic ramifications (Yamamoto et al., 1985). The axonal projections, which could be followed 1.5 $\mathrm{mm}$ from the soma, pursued rostrolateral course toward the cerebral cortex.

Spontaneous transitions between interictal and ictal periods were characterized in VM thalamic cells by a switch from arrhythmic, single-spike activity to burst firing mode (Fig. 2A2). Across cells, the mean firing frequency during interictal periods was $2.40 \pm 0.24 \mathrm{~Hz}$ (from 0.12 to $4.84 \mathrm{~Hz} ; n=30$ cells) (Fig. 2 B1). During SWDs, the firing rate of thalamic neurons reached a mean value of $7.86 \pm 0.72 \mathrm{~Hz}$ (range, $2.20-17.28 \mathrm{~Hz}$; 

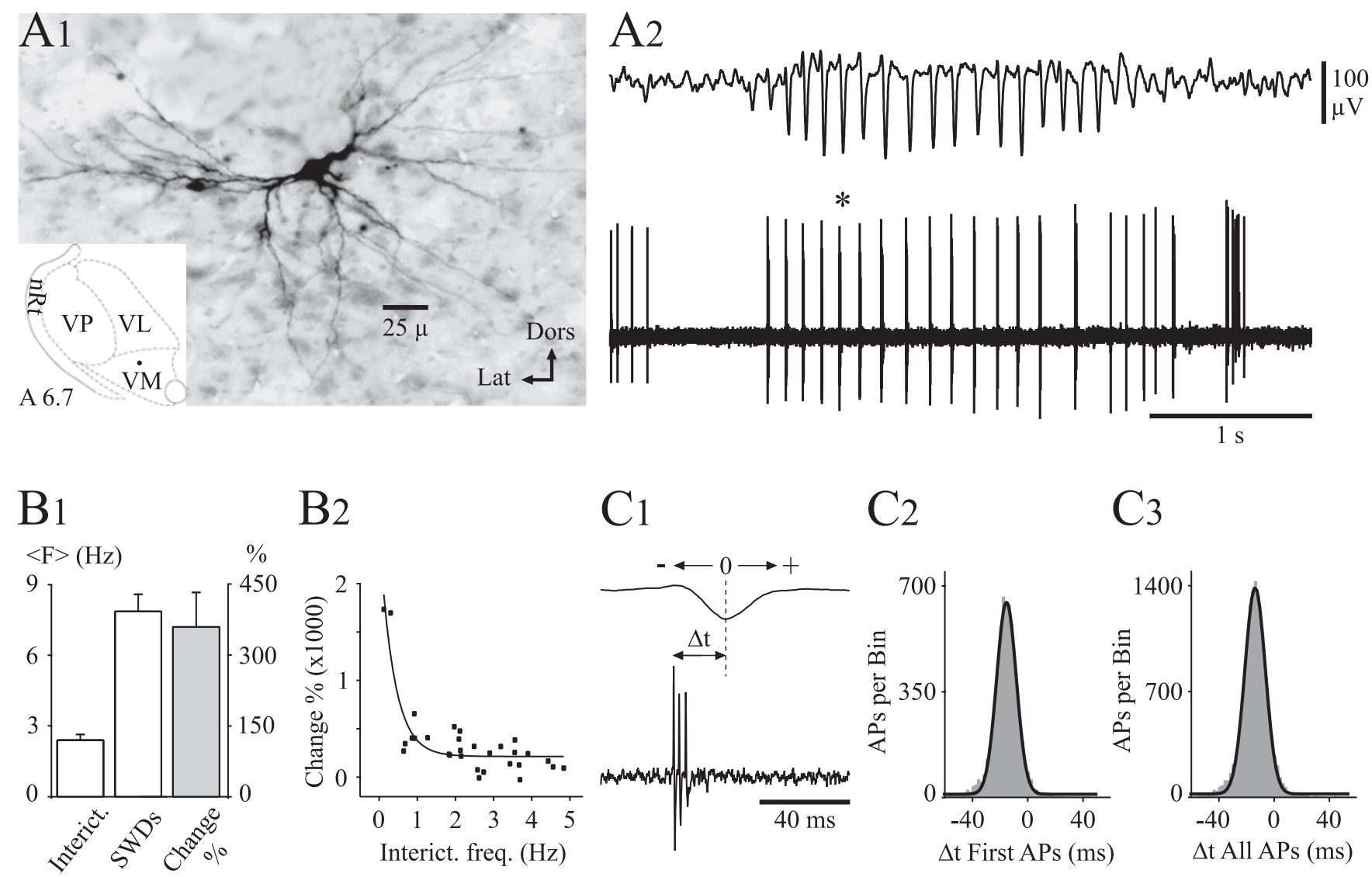

$\mathrm{C}_{2}$

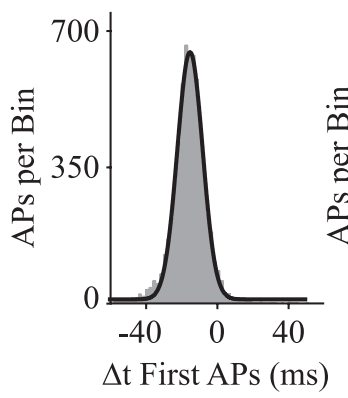

C3

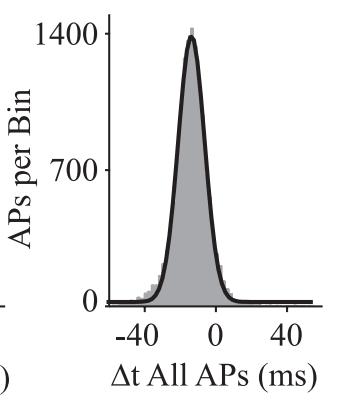

Figure 2. Extracellularly recorded activity of VM thalamic neurons during SWDs. A1, Microphotograph of a VM thalamic neuron labeled by juxtacellular injection of neurobiotin. The cell body (filled circle in the inset; schematic horizontal plane drawing) was located in the central region of the VM thalamic nucleus (at the indicated anterior level with respect to the interaural line) related to the orofacial motor cortex. A2, The background single-spike firing of the VM thalamic neuron (bottom trace) shown in $\mathbf{A}$ was transformed into a high-frequency burst pattern during SWD in the cortical EEG (top trace). The EEG and intracellular activities indicated by the asterisk are expanded in $\mathbf{C 1}$. B1, The mean firing frequency ( $\langle\mathrm{F}\rangle)$ of VM thalamic neurons $(n=30)$ was significantly $(p<$ 0.001) enhanced during SWDs $(n=659)$ compared with the interictal (Interict.) periods, with a mean percentage of increase of $359.3 \pm 73.1 \%$ ( $n=30$ cells). B2, The percentage of firing frequency (freq.) increase decayed exponentially $\left(r^{2}=0.80\right)$ as a function of the interictal firing rate. $\mathbf{C}-\mathbf{C}$, Pooled histograms $(n=30$ neurons) showing the distribution of latencies $(\Delta t)$ of the first $(\boldsymbol{C} 2)$ and of all (C3) action potentials in a burst with respect to the peak negativity of the EEG spike (the method of measurement is indicated in (1). In both histograms, the distribution was best fitted by a Gaussian fit (first action potential, bin size, $2 \mathrm{~ms} ; r^{2}=0.99$; all action potentials, bin size, $2 \mathrm{~ms} ; r^{2}=0.99$ ). $\boldsymbol{A 1}$, $\boldsymbol{A 2}$, and $\mathbf{C}$ are from the same cell. AP, Action potential; Dors, dorsal; Lat, lateral; $\mathrm{nRT}$, thalamic reticular nucleus; VL, ventral lateral thalamic nucleus; VM, ventral medial thalamic nucleus; VP, ventral posterior thalamic nuclei. Error bars represent SEM.

$n=659$ SWDs from 30 cells) (Fig. 2 B1) corresponding to a probability of discharge associated with individual EEG spikes of $0.42 \pm 0.03$ (from 0.07 to $0.80 ; n=30$ cells). The end of cortical paroxysms could be associated in VM thalamic cells $(n=20$ cells $)$ with a transient period of excitation manifested by repetitive discharges of action potentials (Fig. 2A2). The percentage increase in firing rate of VM thalamic neurons during SWDs declined exponentially as a function of the mean interictal firing rate (Fig. 2 B2) and had a mean value of $359.3 \pm 73.1 \%(n=30$ cells $)$ (Fig. 2 B1).

Cortical epileptic discharges also resulted in a drastic change in the firing pattern of VM thalamic neurons, which was characterized by high-frequency bursts of action potentials shortly before the spike component of the EEG (Figs. 2A2,C1;3A,B2). Bursts contained from two to six action potentials $(2.69 \pm 0.01$; $n=4548$ bursts from 670 SWDs; $n=30$ neurons) (Figs. 2C1, $3 B 2$ ) and had a duration of $4.81 \pm 0.03 \mathrm{~ms}$ (range, $2.10-30.81 \mathrm{~ms}$; $n=4548$ ), with a mean intraburst frequency of $355.01 \pm 0.94 \mathrm{~Hz}$ (range, $74.96-543.48 \mathrm{~Hz} ; n=4548$ bursts). The delay of the first action potential, using the peak of the corresponding EEG spike component as the zero-time reference, was $-15.84 \pm 0.12 \mathrm{~ms}$ ( $n=6261$ action potentials from 670 SWDs; $n=30$ cells) (Fig. 2C2). A similar analysis using all action potentials in a burst indicated a mean delay of $-14.05 \pm 0.09 \mathrm{~ms}(n=14,070$ action potentials from 4548 bursts in 670 SWDs; $n=30$ cells) (Fig. 2C3).

\section{Multiunit recordings}

We could perform simultaneous extracellular recordings of two units ( $n=3$ pairs from two GAERS) in the VM thalamus (Fig. $3 A$ ). These multiunit recordings highlighted how typically random firing patterns of neighboring thalamic neurons in the absence of paroxysms (Fig. 3B1,B3) became highly correlated and time-locked to the EEG spike during SWDs (Fig. 3B2,B4). They also indicated that the first action potential in a burst from one VM unit could either precede or follow the first action potential in the concomitant burst of the neighboring cell, with a mean delay between these two action potentials of $5.33 \pm 0.58 \mathrm{~ms}$ (range, $0.4-37.9 \mathrm{~ms} ; n=368$ delays from 75 SWDs; $n=3$ double-unit recordings) (Fig. $3 C$ ). Consistent with the singleunit recordings (Fig. 2A2), the cessation of SWDs was associated in the two simultaneously recorded thalamic neurons with a rebound of excitation evident as either single action potentials (Fig. $3 A$, gray unit) or long clusters of $4-14$ action potentials (Fig. $3 A$, black unit). During multiunit recording experiments, both extracellularly recorded cells could be labeled by the juxtacellular injection of Neurobiotin (Fig. 3D). 


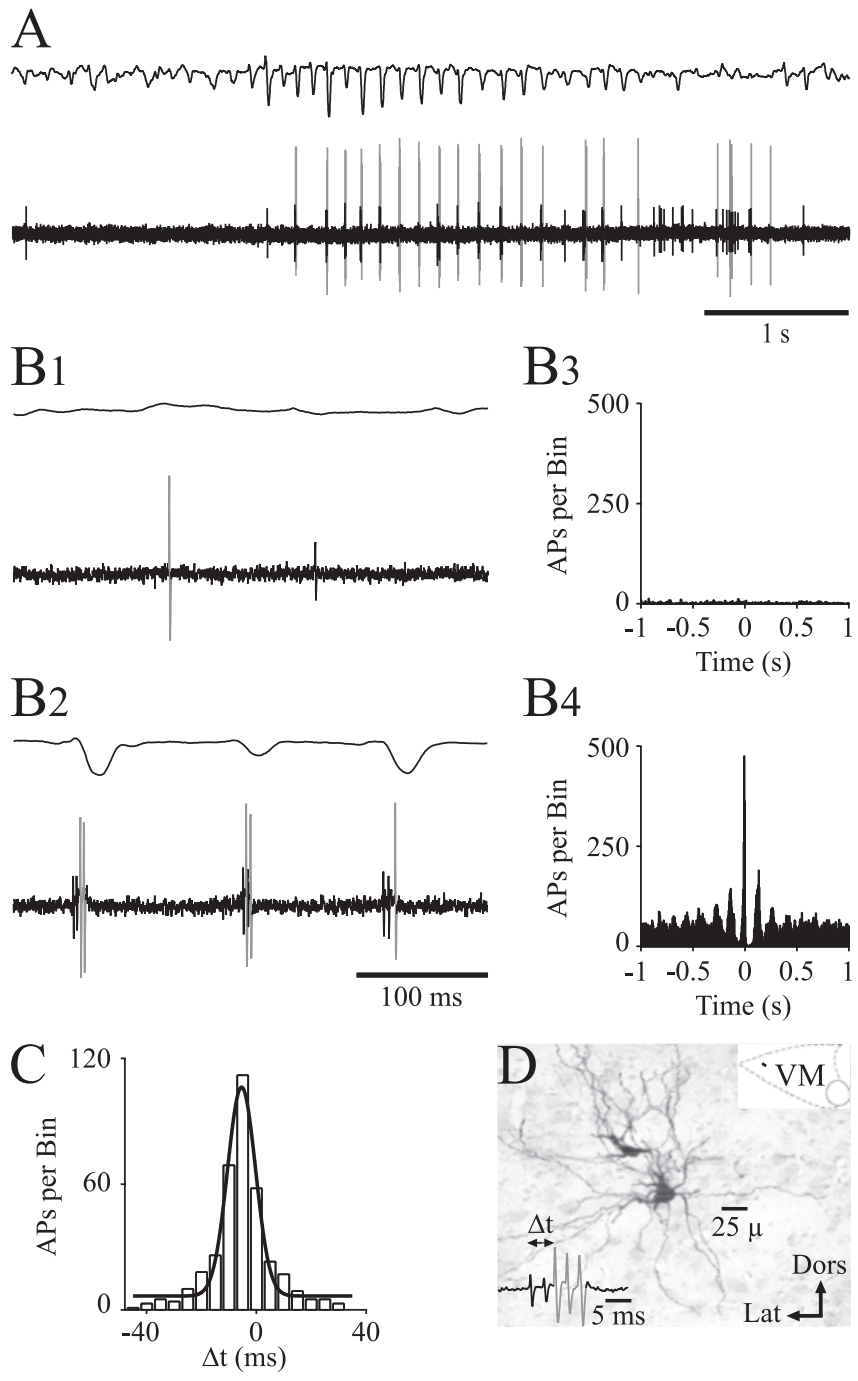

Figure 3. Synchronized bursting in VM thalamic neurons during SWDs. $\boldsymbol{A}$, Simultaneous recording of two VM thalamic units (black and gray action potentials) and the cortical EEG. Note the brief increase of firing in both units just after the seizure. B1, B2, The randomly occurring action potentials in two neighboring cells during interictal activity $(\boldsymbol{B} 1)$ became highly synchronized bursts, tightly correlated with the EEG spike during SWDs (B2). Time calibration in B2 also applies to $\boldsymbol{B}$ 1. $\boldsymbol{B} 3, \boldsymbol{B} 4$, The synchronization of the two units by the SWD is clearly shown by the cross-correlation plots before (B3) and during (B4) seizures (bin size, $5 \mathrm{~ms} ; 160$ s samples). $\boldsymbol{C}$, Histogram (white bars) and Gaussian distribution (black line) showing the relative timing $(\Delta t)$ of the first action potentials of concomitantly occurring bursts in the two units ( $n=368$ values from three double units; bin size, $5 \mathrm{~ms}$; Gaussian fit, $r^{2}=0.97$ ). The method of measurement is indicated in the inset in D. D. Microphotograph of two simultaneously recorded VM thalamic units (bottom inset) located in a lateral region of the VM thalamic nucleus (filled circle in the top inset; schematic horizontal plane drawing) related to the orofacial motor cortex. Anteriority relative to the interaural line was $6.7 \mathrm{~mm}$. $\boldsymbol{A}$ and $\boldsymbol{B}$ are from the same double-unit recording. AP, Action potential; Dors, dorsal; Lat, lateral; VM, ventral medial thalamic nucleus.

\section{Intracellular recordings of VM thalamic neurons: electrical membrane properties}

The hyperactivity of GAERS VM thalamic neurons during SWDs might result from an alteration of their intrinsic excitability. To test this hypothesis, we used intracellular recordings to compare passive and active electrical membrane properties of VM thalamic cells in GAERS ( $n=14$ cells from 10 GAERS) and nonepileptic rats ( $n=9$ cells from 7 Wistar rats). We first examined the membrane $V-I$ relationship, which was determined during interictal periods in GAERS, by measuring membrane potential changes in response to a series of intracellular square current pulses (Fig. 4A1,A2,B1,B2). The apparent input resistance, measured from the linear portion of the $V-I$ plot (Fig. 4A2,B2), was similar in both rat strains (Table 1). In both cell populations, a marked inward rectification was consistently observed in response to negative current pulses of high intensity (Fig. $4 A 1, A 2, B 1, B 2)$. This resulted from a depolarizing "sag" of membrane potential (Fig. 4A1,B1, arrow), likely caused by the hyperpolarization-activated inward cationic current $\left(I_{\mathrm{h}}\right)(\mathrm{Mc}-$ Cormick and Pape, 1990). Large-amplitude current-induced hyperpolarizations were systematically followed by a rebound of depolarization (Fig. $4 A 1, B 1$, arrowhead) that might result from a mixture of the low-threshold activated calcium current $\left(I_{\mathrm{T}}\right)$ (Llinas and Jahnsen, 1982; Steriade et al., 1990) and $I_{\mathrm{h}}$. A characteristic electrical feature of relay thalamic neurons (Llinas and Jahnsen, 1982; Steriade et al., 1990) was that depolarizing current pulses applied from the resting potential generated a tonic firing pattern in VM thalamic cells of both GAERS and control animals (Fig. 4A1;A3, left;B1;B3, left). During DC hyperpolarization, which deinactivates $I_{\mathrm{T}}$ (Steriade et al., 1990), the same current pulse induced in both cell populations a low-threshold $\mathrm{Ca}^{2+}$ potential (LTCP) crowned by a burst of $\mathrm{Na}^{+}$action potentials (Fig. 4A3;B3, right panels). Moreover, basic electrical membrane properties of thalamic cells, including membrane potential, membrane time constant, and action potentials properties, were similar in both GAERS and normal rats (Table 1).

Because passive and active intrinsic membrane properties of VM thalamic neurons recorded from GAERS and normal Wistar rats did not differ significantly, it is unlikely that the sustained bursting activity of thalamic cells during SWDs was caused by an alteration in their intrinsic excitability.

\section{Intracellular recordings of VM thalamic neurons: cellular events associated with absence seizures}

In vivo intracellular recordings from GAERS VM thalamic neurons $(n=14)$ confirmed and extended the observations made with extracellular recordings. Intracellularly and extracellularly recorded cells were located in the same thalamic region and exhibited identical morphological features (data not shown). When an SWD appeared in the EEG, the firing of VM thalamic cells switched from single spike activity to burst firing (Fig. 5A1), accompanied by membrane potential oscillations temporally correlated with spike-wave complexes (Fig. 5A1,A2). Repetitive membrane depolarizations were superimposed on a "croissant"shaped hyperpolarizing envelope of amplitude $12.2 \pm 1.1 \mathrm{mV}$ (range, $6.6-20.1 \mathrm{mV} ; n=14$ cells) that lasted for the entire SWD (Fig. 5A1). Measurements of hyperpolarizing envelope amplitude as a function of the membrane potential (data not shown), which was maintained at different levels of polarization by DC injections, indicated a virtual reversal potential of approximately $-100 \mathrm{mV}$, consistent with the equilibrium potential of $\mathrm{K}^{+}$in thalamic neurons (Destexhe and Sejnowski, 2001).

The suprathreshold oscillations in thalamic neurons during SWDs were composed of temporally summating high-frequency synaptic potentials (Fig. 5A2, inset) and a LTCP-like depolarization (Fig. $5 A 2$, arrow) giving rise to multiple $\mathrm{Na}^{+}$action potentials, whereas subthreshold events (Fig. 5A2, crossed arrow) were characterized by a smooth depolarizing rising phase $(\sim 40 \mathrm{~ms}$ duration) followed by a slower ( $\sim 100 \mathrm{~ms}$ duration) decaying component.

The end of the SWD in the cortical EEG coincided with the cessation of intracellular thalamic oscillations and of the hyperpolarization (Fig. 5A1). The membrane repolarization was often ( $n=40$ SWDs from nine GAERS) followed by repetitive firing 
(Fig. 5A1) similar to the postictal discharge observed during extracellular recordings (Figs. 2A2, 3A).

\section{Intracellular recordings of VL thalamic neurons}

In the course of thalamic recordings, we obtained intracellular records $(n=5)$ (Fig. 6) from the GAERS VL thalamic nucleus, which is located just above the VM thalamic nucleus (see Materials and Methods). Ventral lateral thalamic cells had a mean interictal membrane potential $(-58.0 \pm 1.7 \mathrm{mV} ; n=5$ cells $)$, apparent input resistance $(25.6 \pm 1.8 \mathrm{M} \Omega ; n=5$ cells), and membrane time constant $(13.5 \pm 1.9 \mathrm{~s} ; n=5$ cells $)$ similar $(p>0.3$ for each parameters) to that calculated in VM thalamic neurons (Table 1). During interictal periods, thalamic VL cells exhibited a mean firing frequency $(2.21 \pm 0.55$ $\mathrm{Hz} ; n=5$ cells) (Fig. 6A1) comparable $(p>0.9)$ to that of VM thalamic units (Fig. 2 B1). As observed in intracellularly recorded VM thalamic cells (Fig. 5A1), the occurrence of cortical paroxysms were accompanied in VL thalamic cells with membrane oscillations (Fig. 6A1,A2) superimposed on a croissant-shaped hyperpolarization (Fig. 6A1). However, in contrast with VM thalamic cells that showed a significant increase in their mean firing rate during SWDs (Fig. 2 B1,B2), the rate of discharge in VL thalamic neurons was not significantly modified by the seizures $(1.31 \pm 0.21 \mathrm{~Hz} ; n=47$ SWDs from five cells; $p>0.5$ ) (Fig. 6A1) and was markedly lower $(p<0.001)$ to that measured in VM thalamic cells (Fig. 2B1). This relative weak activity of VL thalamic cells during SWDs was not attributable to a specific alteration in their intrinsic excitability because they exhibited, as VM thalamic neurons (Fig. 4A1), the typical active membrane properties of thalamocortical neurons, including a depolarizing sag of membrane potential during current-induced membrane hyperpolarization, a postinhibitory rebound of depolarization and a tonic firing pattern in response to depolarizing current pulses applied from the resting potential (Fig. 6A3).

\section{Association strength and temporal relationship between VM intracellular oscillations and cortical SWDs}

To assess the functional links and the directionality of information flow between the cerebral cortex and the VM thalamic nucleus, we measured the strength of association $\left(h^{2}\right)$ (see Materials and Methods) and the temporal delays between EEG and thalamic intracellular activities. As illustrated in Figure 5B, the seizure onset was characterized by a gradual increase in the degree of association between the signals and, after reaching a maximum in the middle of the crisis, $h^{2}$ progressively recovered its preictal value. From four paired recordings of surface cortical and intracellular thalamic activities ( $n=23$ seizures), the average degree of association between both signals during the first second of the
SWD $\left(h^{2}=0.38 \pm 0.13 ; n=23\right.$ SWDs $)$ was significantly higher than before the ictal epoch $\left(h^{2}=0.19 \pm 0.12 ; p<0.001\right)$. Furthermore, values for the time delay derived from nonlinear correlation of EEG waves and the intracellular activity of VM thalamic cells were profoundly modified by the seizure (Fig. 5B2). Before SWDs, low values for $h^{2}$ were associated with highly variable time delays. In contrast, as the seizure began, a clear and stable time lag emerged between thalamic intracellular and cortical EEG rhythmic activities and was maintained throughout the SWD (Fig. 5B2). For the 23 analyzed seizures, oscillatory thalamic signals preceded the cortical oscillations by $12.2 \pm 8.5 \mathrm{~ms}$.

\section{Blockade of cortical SWDs after intranigral injection of kynurenate}

GABAergic projections of the SNR to VM thalamocortical neurons provide a potent feedback to the cerebral cortex that could underlie the control of absence seizures by the basal ganglia (see Introduction). To test this hypothesis, we first examined the impact on the EEG of intranigral injection of a glutamate receptor antagonist (kynurenate), expected to block the intranigral glutamatergic transmission, mainly originating from the subthalamus (Smith and Parent, 1988; Robledo and Feger, 1990), and decrease 
Table 1. Comparison of membrane properties of VM thalamic neurons in GAERS and nonepileptic Wistar rats

\begin{tabular}{lllllll}
\hline & $V_{\mathrm{m}}(\mathrm{mV})$ & $R_{\text {in }}(\mathrm{M} \Omega)$ & $\tau(\mathrm{ms})$ & AP threshold $(\mathrm{mV})$ & AP amplitude $(\mathrm{mV})$ & AP duration $(\mathrm{ms})$ \\
\hline Control & $-58.9 \pm 1.1(9)$ & $22.9 \pm 2.1(8)$ & $12.2 \pm 1.1(8)$ & $-49.3 \pm 0.5(9)$ & $47.1 \pm 1.9(9)$ & $1.18 \pm 0.06(9)$ \\
GAERS & $-60.3 \pm 1.1(14)$ & $25.2 \pm 1.3(12)$ & $17.8 \pm 2.7(12)$ & $-50.8 \pm 0.4(14)$ & $46.3 \pm 1.8(14)$ & $1.19 \pm 0.05(14)$ \\
\hline
\end{tabular}

The electrical membrane properties of VM thalamic neurons recorded from GAERS and nonepileptic Wistar rats did not differ significantly $(p>0.05$ for all parameters, $t$ test). The number of cells for each parameter is indicated in parentheses. $\mathrm{AP}$, Action potential; $R_{\mathrm{in},}$, membrane input resistance; $\tau$, membrane time constant; $V_{\mathrm{m}}$, interictal mean membrane potential.

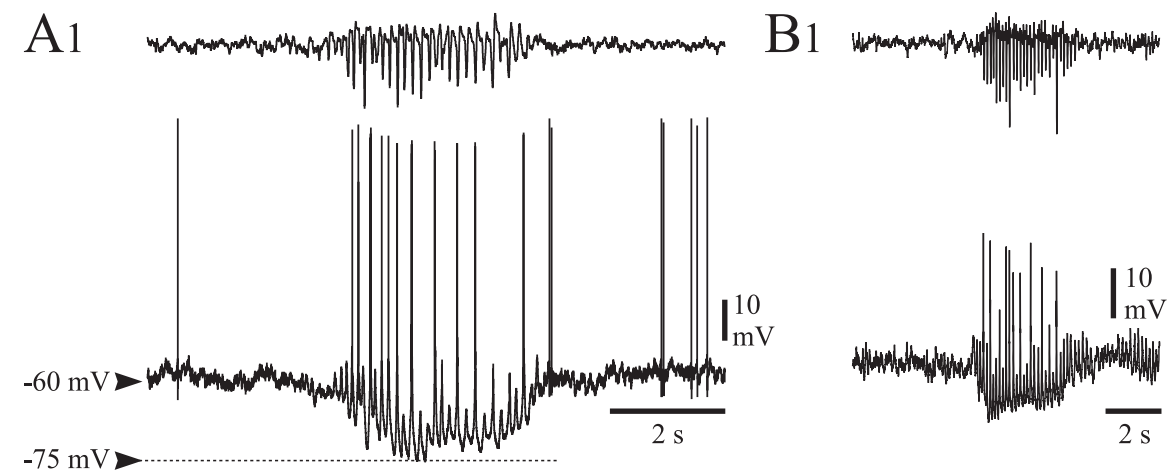

A2
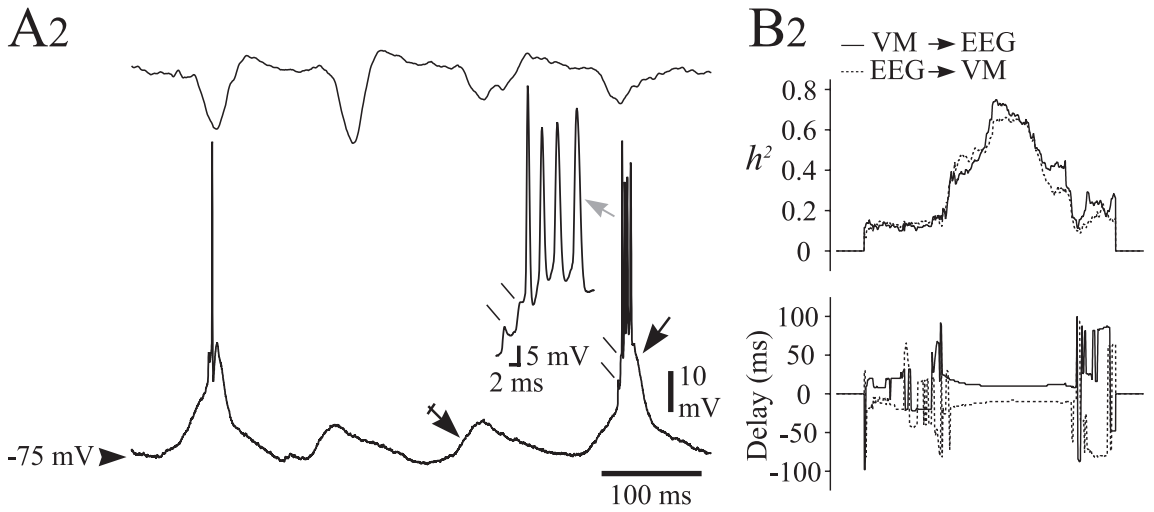

Figure 5. Membrane potential oscillations in VM thalamic neurons during SWDs and their relationship to cortical EEG waves. A1, Spontaneous intracellular activity of a VM thalamic neuron (bottom trace) simultaneously recorded with the cortical EEG (top trace). The interictal random firing of VM thalamic neurons was converted, during SWDs, into a bursting mode generated by rhythmic depolarizations, which were superimposed on a croissant-shaped hyperpolarization (dashed line). A2, Expansion of the ictal EEG (top trace) and its cellular correlate in the simultaneously recorded VM thalamic cell (bottom trace). The expanded record in the inset indicates that the suprathreshold depolarization (black arrow) was associated with the temporal summation of small-amplitude depolarizing potentials, which were lacking during subthreshold events (crossed arrow). $\boldsymbol{B}$, Temporal evolution of the relationships between EEG and intracellular activities of VM thalamic neurons. B1, Typical EEG paroxysm (top trace) and its filtered intracellular correlate in a simultaneously recorded VM thalamic cell (bottom trace). Both EEG and intracellular signals were downsampled at $1000 \mathrm{~Hz}$. B2, Top, Time course of the strength of association between the cortical and thalamic activities shown in $\boldsymbol{B}$ 1. The nonlinear correlation indices $\boldsymbol{h}^{2}$ (EEG-VM, dashed line; VM-EEG, continuous line) were calculated for successive 2 s windows with a temporal overlapping of $98 \%$. B2, Bottom, Corresponding time delays. The time lag values fluctuated before and after the paroxysm but were relatively constant during the SWD. This result is consistent with a directional coupling during the main body of the seizure, from the VM thalamic nucleus to the cerebral cortex, with a delay of $\sim 12 \mathrm{~ms}$. The traces in $\boldsymbol{B} 1$ and the corresponding analysis in $\boldsymbol{B} \mathbf{2}$ are temporally aligned. $\boldsymbol{A}$ and $\boldsymbol{B}$ are from two different neurons.

the activity of SNR cells (see below). A unilateral injection of 100 $\mathrm{nl}$ of kynurenate in SNR abolished ipsilateral SWDs in both motor and somatosensory cortices (Fig. 7) for $20 \pm 3.7 \mathrm{~min}(n=13$ injections with recovery). After recovery, which occurred simultaneously in both cortical regions, cortical paroxysms had a duration ( $8.29 \pm 0.74 \mathrm{~s} ; n=368$ SWDs $)$ and a period of recurrence $(55.58 \pm 5.40 \mathrm{~s} ; n=352$ inter-SWD intervals) similar $(p>0.05$ for both parameters) to that calculated during preinjection periods (control duration, $6.78 \pm 0.40 \mathrm{~s} ; n=513$ SWDs; control inter-SWD intervals, $51.76 \pm 4.96 \mathrm{~s} ; n=489$ ).

The specificity of kynurenate injection in the blockade of generalized seizures was attested by the lack of EEG changes after intranigral vehicle injections $(0.9 \% \mathrm{NaCl} ; 100-200 \mathrm{nl} ; n=5$ injections) (Fig. 8A). Duration of cortical paroxysms (before vehicle, $7.51 \pm 0.58 \mathrm{~s}$; $n=194$ SWDs; after vehicle, $7.76 \pm 0.54 \mathrm{~s}$; $n=130$ SWDs) as well as the inter-SWD interval (before vehicle, $22.39 \pm 1.99 \mathrm{~s} ; n=$ 189; after vehicle, $18.42 \pm 2.21 \mathrm{~s} ; n=125$ ) were not significantly modified by the vehicle injection $(p>0.1$ for both parameters).

\section{Effect of intranigral injections of kynurenate on the activity of SNR and VM thalamic neurons}

To determine the mechanisms of control of absence seizures by the nigrothalamic pathway, we first correlated the antiepileptic effects of intranigral injection of kynurenate with changes in activity of SNR and VM thalamic neurons.

In control conditions, extracellularly recorded SNR neurons $(n=11$ from five GAERS) showed an elevated interictal firing rate of $19.30 \pm 1.01 \mathrm{~Hz}(n=11$ cells $)$. In five recordings, of duration sufficient to test the effect of kynurenate injection, the blockade of SWDs was associated with a significant decrease in the firing rate of nigral neurons (before kynurenate, $19.72 \pm$ $0.94 \mathrm{~Hz}$; after kynurenate, $4.17 \pm 2.40 \mathrm{~Hz}$; $n=5$ cells; $p<0.001$ ) (Fig. 8, compare B1, $B 2 ; D 1)$. The recovery of seizures was concomitant with a restoration of the interictal firing activity of SNR neurons (22.42 \pm $2.95 \mathrm{~Hz} ; n=4$ cells; $p>0.4$, control vs recovery) (Fig. 8, compare $B 3, B 1 ; D 1$ ).

In this set of experiments, the five extracellularly recorded VM thalamic neurons had, during control condition, a mean interictal firing rate of $0.93 \pm 0.08 \mathrm{~Hz}$ (Fig. $8 C 1, C 2, D 2)$. As expected from the inhibitory influence of SNR on VM thalamic nucleus (Deniau and Chevalier, 1985), the pharmacological blockade of glutamatergic transmission in the SNR, which also interrupted SWDs, was reflected in thalamic cells by a marked increase in firing rate $(4.46 \pm 2.26 \mathrm{~Hz} ; n=4$ cells; $p<0.01$, control vs kynurenate) (Fig. 8C1,C3). The restoration of SWDs, that could be obtained during three extracellular thalamic records, was correlated with a recovery in the interictal firing rate of VM thalamic neurons $(1.59 \pm 0.31 \mathrm{~Hz} ; n=3$ cells; $p>0.2$, control vs recovery) (Fig. $8 C 1, C 4, D 2)$.

Demonstrating the specific action of intranigral injection of kynurenate, vehicle injections $(0.9 \% \mathrm{NaCl} ; 100-200 \mathrm{nl} ; n=5)$ into the SNR had no effect on either firing frequency of VM neurons (before vehicle, $1.43 \pm 0.15 \mathrm{~Hz}, n=10$ cells; after vehi- 

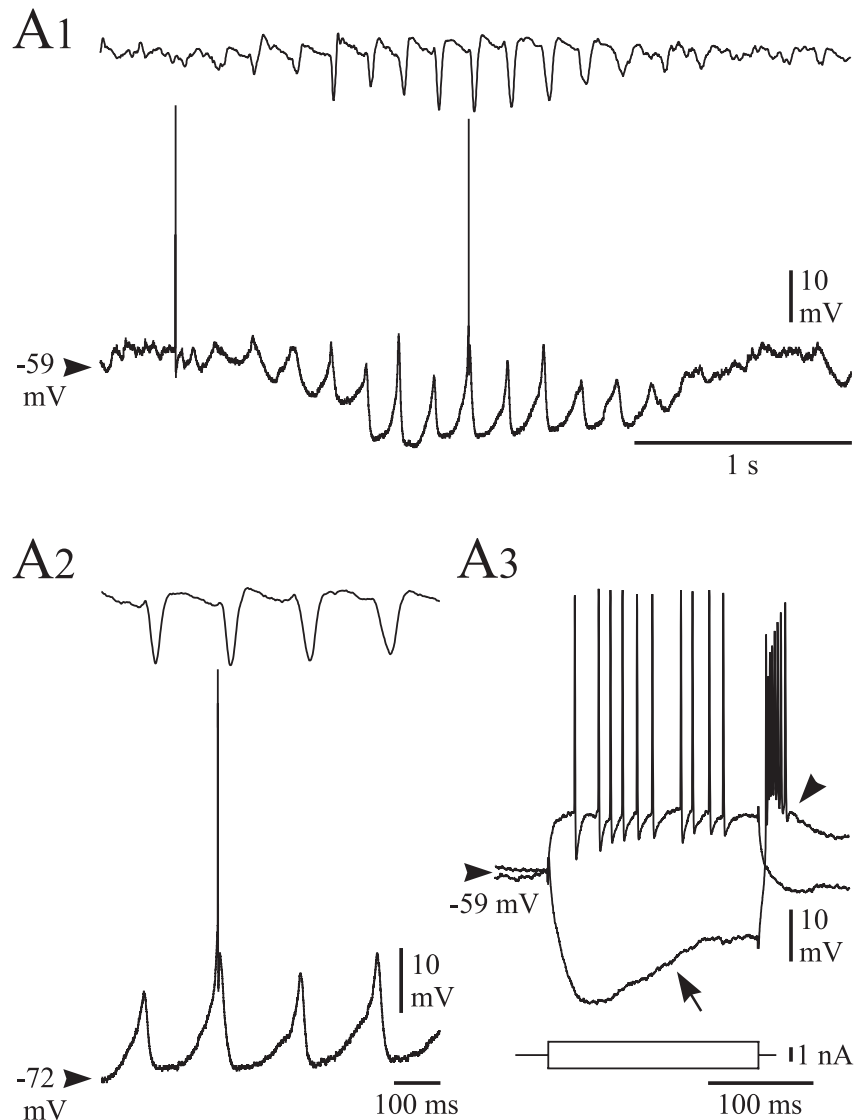

Figure 6. Subthreshold membrane potential oscillations in VL thalamic neurons during SWDs. A1, Spontaneous intracellular activity of a VL thalamic neuron (bottom trace) simultaneously recorded with the cortical EEG (top trace). The occurrence of an SWD in the EEG was accompanied, in the thalamic cell, with subthreshold rhythmic membrane depolarizations superimposed on a sustained hyperpolarization. $\mathbf{A 2}$, Expansion of the ictal EEG (top trace) and its intracellular correlate in the simultaneously recorded VL thalamic cell (bottom trace). A3, Voltage responses of the same $V L$ thalamic neuron (top traces) to intracellular injection of positive and negative square current pulses of same intensity (bottom traces). Note the hyperpolarization-activated depolarizing sag (arrow) generated by the negative current pulse. At the break of the negative current pulse, the cell exhibited a rebound response (arrowhead) eliciting a burst of action potentials. $\boldsymbol{A} \mathbf{1}-\mathbf{A} \mathbf{3}$ are from the same cell.

cle, $1.36 \pm 0.17 \mathrm{~Hz}, n=5$ cells; $p=0.6)$ or cortical EEG pattern (Fig. $8 A$ ).

\section{Intranigral injection of kynurenate decreases cortical neurons excitability}

To determine the cortical mechanisms underlying the control of absence seizures by the SNR, we examined the effect of intranigral injections of kynurenate on simultaneously recorded EEG and cortical intracellular activities. In the 10 intracellularly recorded cortical cells, the activity between seizures, before kynurenate injection, was characterized by irregular, depolarizing and hyperpolarizing, membrane potential fluctuations that generated a random firing pattern at a mean frequency of $3.05 \pm 0.24 \mathrm{~Hz}$ (Fig. 9A1). SWDs were accompanied in cortical neurons with repetitive membrane depolarizations superimposed on a tonic hyperpolarization that lasted for the entire surface paroxysm. These interictal and ictal intracellular activities are similar to those previously described in the same orofacial cortical region of GAERS (Charpier et al., 1999; Slaght et al., 2004; Paz et al., 2005a,b). After kynurenate application, the suppression of SWDs was

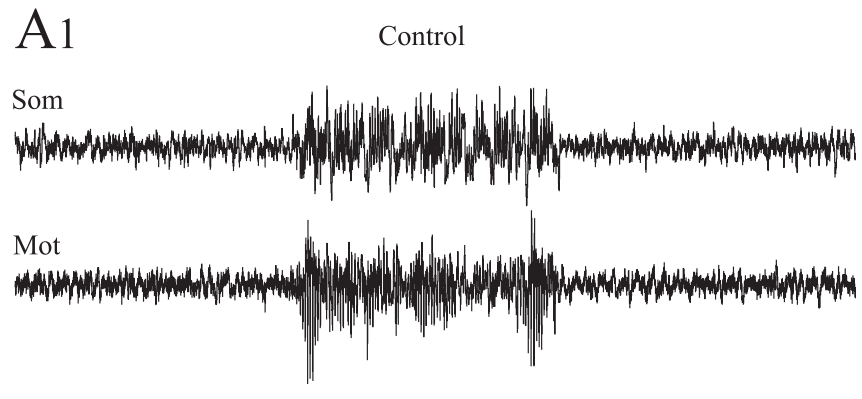

A2 KYNU/SNR

Som

Mot

(1)

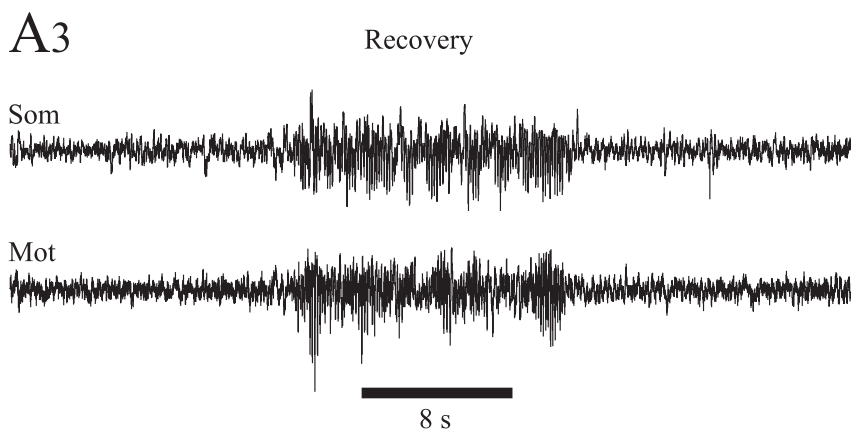

Figure 7. Blockade of cortical SWDs by intranigral injections of kynurenate. Simultaneous recordings of motor orofacial (Mot) and somatosensory (Som) cortical EEGs, 16 min before (A1) and $10 \mathrm{~min}(\boldsymbol{A 2})$ and $100 \mathrm{~min}(\boldsymbol{A 3})$ after injection of KYNU in the SNR. Motor and somatosensory cortical SWDs were concomitantly interrupted in both cortices $(\boldsymbol{A 2})$ and recovered simultaneously (A3).

correlated with a significant decrease in cortical neuron firing frequency $(0.44 \pm 0.25 \mathrm{~Hz} ; n=10$ cells; $p<0.001)$ (Fig. 9A2). When intracellular recordings were kept until recovery of SWDs ( $n=7$ cells), the interictal firing rate of cortical cells was restored close its baseline value $(2.19 \pm 0.28 \mathrm{~Hz} ; n=7$ neurons) (Fig. 9A3). Moreover, the cellular correlates of surface paroxysms (Fig. 9A3) were similar to those observed during control periods.

The kynurenate-induced decrease in cortical activity was associated with changes in the passive membrane properties of cortical cells. The membrane potential of recorded cells (before injection, $-58.03 \pm 0.42 \mathrm{mV} ; n=10$ cells) hyperpolarized significantly after intranigral application of kynurenate $(-64.64 \pm 1.33 \mathrm{mV} ; n=10$ cells; $p<0.001)$ (Fig. $9 A 1, A 2, B, D$, top). This was correlated with a decrease in apparent input resistance (before kynurenate, $25.67 \pm 1.67 \mathrm{M} \Omega$, $n=10$ cells; vs after kynurenate, $18.77 \pm 1.31 \mathrm{M} \Omega, n=9$ cells; $p<0.001$ ) (Fig. 9C, $D$, middle) and time constant (before kynurenate, $12.13 \pm 1.07 \mathrm{~ms}, n=10$ cells; vs after kynurenate, $7.67 \pm 0.37 \mathrm{~ms}, n=9$ cells; $p<0.001$ ) (Fig. 9C,D, bottom). $V-I$ relationships of cortical neurons, during both preinjection and postinjection periods, were linear (apparent input resistance was independent of the level of membrane polariza- 

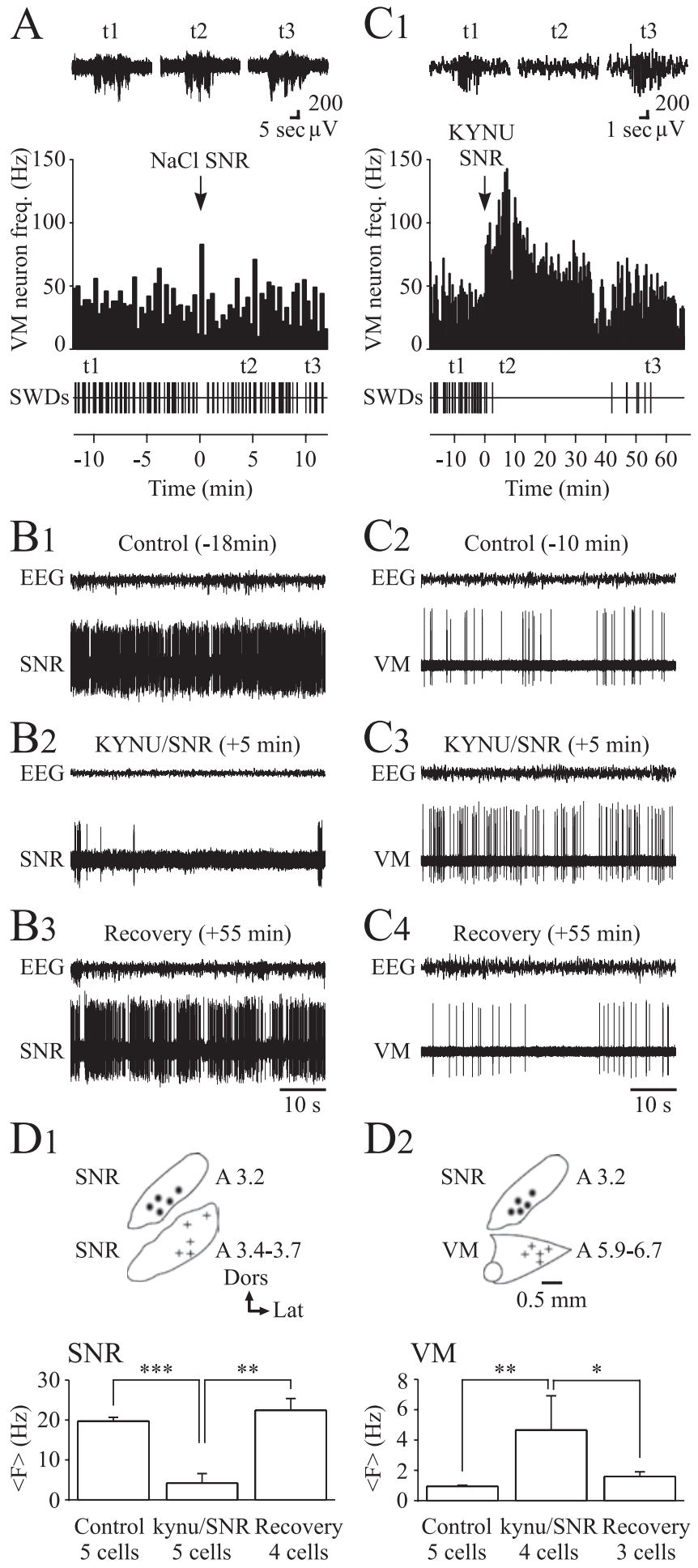

Figure 8. Effects of intranigral injection of kynurenate on the activity of SNR and VM thalamic neurons. $\boldsymbol{A}$, Intranigral application of a vehicle solution did not affect neither the activity of thalamic neurons nor cortical SWDs. The histogram represents the mean firing frequency of a VM thalamic neuron (bin, $20 \mathrm{~s})$ at the indicated times before and after vehicle $(0.9 \% \mathrm{NaCl})$ injection, taken as time 0 . Each vertical bar below the histogram indicates the occurrence of a SWD in the corresponding EEG. The top records in $\boldsymbol{A}$ show spike-and-wave activities recorded before (t1) and after $(\mathrm{t} 2, \mathrm{t} 3)$ the vehicle application. $\boldsymbol{B}$, Intranigral injection of kynurenate inhibits SNR neurons. $\boldsymbol{B} 1-\mathbf{B}$, Simultaneous recordings of interictal motor cortex EEG and extracellular activity of a SNR neuron before $(\boldsymbol{B} 1)$ and after $(\boldsymbol{B 2}, \mathbf{B} 3)$ KYNU application. $\boldsymbol{C}$, Intranigral injection of kynurenate excites VM thalamic neurons. C1, Histogram representing the mean firing frequency (freq.) of a VM thalamic neuron (bin, $20 \mathrm{~s}$ ) at the indicated times before (t1) or after $(\mathrm{t} 2, \mathrm{t} 3)$ injection of kynurenate in the SNR. Each vertical bar below the histogram indicates the occurrence of an SWD in the corresponding EEG. Note that the disappearance of SWDs in the tion) (data not shown), indicating that the reduction in input resistance was not attributable to an inward rectification at membrane potentials reached after drug injection. Again, the recovery of SWDs led to a recovery of the control membrane input resistance $(26.88 \pm 3.91 \mathrm{M} \Omega ; n=6$ cells; $p>0.7$, control vs recovery) and time constant ( $9.77 \pm 0.55 \mathrm{~ms} ; n=6$ cells; $p>0.1$, control vs recovery) (Fig. $9 D$, middle and bottom). The diminution in cortical neurons firing rate did not result from changes in action potential properties. Their duration (before kynurenate, $1.68 \pm 0.10 \mathrm{~ms}, n=10$ cells; vs after kynurenate, $1.60 \pm 0.09 \mathrm{~ms}, n=10$ cells), amplitude (before kynurenate, $59.10 \pm 1.90 \mathrm{~ms}, n=10$ cells; vs after kynurenate, $60.20 \pm 2.9 \mathrm{~ms}, n=10$ cells) and voltage threshold (before kynurenate, $-50.30 \pm 0.60 \mathrm{~ms}, n=10$ cells; vs after kynurenate, $-50.40 \pm 0.70 \mathrm{~ms}, n=10$ cells) were not significantly modified ( $p>0.7$ for each parameter) after kynurenate injection.

\section{Discussion}

The present study provides the first description of the activity of VM thalamic neurons during absence seizures and strongly suggests that the nigro-thalamo-cortical network participates in the control of cortical paroxysms. Our main findings are as follows: (1) during SWDs, VM thalamic neurons display synchronized repetitive high-frequency bursts of action potentials in-phase with EEG spikes; (2) intracellular recordings reveal that rhythmic bursting in thalamic cells is generated by LTCP-like depolarizations interacting with synaptic inputs; (3) the apparent hyperexcitability of VM thalamic neurons does not result from an alteration of membrane properties in epileptic animals; (4) pharmacological blockade of glutamatergic transmission in the SNR increases the rate of discharge in VM thalamic cells and leads to an irregular tonic firing pattern correlated with an interruption of cortical SWDs; and (5) this blockade of ictal activity is associated in cortical neurons with a membrane hyperpolarization and a decrease in input resistance.

\section{Membrane oscillations and bursting of VM thalamic neurons during SWDs}

The occurrence of SWDs in the EEG was accompanied in VM thalamic cells with oscillatory depolarizations superimposed on a croissant-shaped hyperpolarization (Fig. 5A1). This intracellular waveform closely resembles that previously described from specific thalamocortical relay neurons in GAERS during spontaneous seizures (Pinault et al., 1998; Pinault, 2003) and in the cat during pharmacologically induced paroxysms (Steriade and Contreras, 1995; Timofeev et al., 1998; Timofeev and Steriade, 2004). The sustained hyperpolarization observed in VM thalamic cells during SWDs apparently reversed near $-100 \mathrm{mV}$. This value

EEG is concomitant with an increase in the VM thalamic cell firing. The top traces depict EEG records at the indicated times. C2-C4, Simultaneous recordings of the interictal motor EEG and the extracellular activity of a VM neuron, before $(\mathbf{C})$ and after $(\mathbf{C}, \mathbf{C 4})$ KYNU injection in the SNR. D1, The mean firing frequency $(\langle\mathrm{F}\rangle)$ of SNR neurons was significantly $\left({ }^{* * *} p<0.001\right.$, control vs kynurenate) decreased after intranigral application of kynurenate and recovered ${ }^{* *} p<0.01$, kynurenate vs recovery) $9-50$ min after drug injection. D2, The mean firing frequency of VM neurons was significantly $\left({ }^{* *} p<0.01\right.$, control vs kynurenate) increased after intranigral injection of kynurenate and was restored $\left({ }^{*} p<0.05\right.$, kynurenate vs recovery) after $\sim 25 \mathrm{~min}$ (from 8 to $39 \mathrm{~min}$ ). The insets in $\mathbf{D 1}$ and $\mathbf{D 2}$ depict simplified representations of the SNR and VM, at the indicated anteriorities, with the sites of kynurenate injections (black dots) and the corresponding location of extracellularly recorded neurons (crosses) in the SNR (D1) and in the VM (D2). Time calibration in $\mathbf{C} 4$ applies also to $\boldsymbol{B} \mathbf{1}-\mathbf{B} 3, \mathbf{C}$, and $\mathbf{C 3}$. 
is close to the equilibrium potential of $\mathrm{K}^{+}$, strongly suggesting the involvement of postsynaptic $\mathrm{K}^{+}$-dependent $\mathrm{GABA}_{\mathrm{B}}$ receptors (Destexhe and Sejnowski, 2001). The activation of these receptors, which generates a similar hyperpolarizing envelope in thalamocortical neurons in a pharmacological model of absence seizures in vitro (Bal et al., 1995), might result from repetitive discharges in converging GABAergic inputs arising from the reticular thalamic nucleus (Steriade and Contreras, 1995; Slaght et al., 2002a) and the SNR (Deransart et al., 2003) (our unpublished observations) during spikeand-wave activity.

The membrane oscillations in VM thalamic neurons during seizures likely result from complex interactions between synaptic and active intrinsic membrane properties. The early phase of thalamic rhythmic depolarizations during SWDs (Fig. 5A2) could be attributable to the activation of $I_{\mathrm{h}}$ (McCormick and Pape, 1990) by the sustained membrane hyperpolarization. The presence of $I_{\mathrm{h}}$ in the recorded neurons was attested by the characteristic depolarizing sag during current-induced hyperpolarizations (Fig. 4A1, arrow) (McCormick and Pape, 1990). Alternatively, the depolarizing phase of thalamic oscillations could originate from excitatory synaptic inputs and/or $\mathrm{Cl}^{-}$-dependent synaptic potentials that might be depolarizing from the membrane potential reached during the hyperpolarizing envelope (approximately $-75 \mathrm{mV}$ ) (i.e., more negative that the $\mathrm{Cl}^{-}$equilibrium potential) (Destexhe and Sejnowski, 2001). These subthreshold rhythmic depolarizations could activate $I_{\mathrm{T}}$, from a deinactivated state caused by the membrane hyperpolarization, and generate an LTCP (Steriade et al., 1990). Such a $\mathrm{Ca}^{2+}$-dependent rebound of excitation, observed at the break of a hyperpolarizing current pulse (Fig. 4A1, oblique arrowhead), could trigger during seizures a single or a burst of $\mathrm{Na}^{+}$action potentials when coincident with a barrage of depolarizing synaptic potentials (Fig. 5A2). These excitatory inputs probably arose from repetitive firing in corticothalamic neurons, a hypothesis consistent with the timing of action potentials discharge in corticofugal axons during absence seizures (Charpier et al., 1999; Pinault, 2003; Slaght et al., 2004; Paz et al., 2005a) and in agreement with the association strength of simultaneously recorded EEG and intracellular thalamic activities during the main body of the seizure (Fig. 5B2).

SWDs in the EEG were associated with a drastic change in the firing pattern of VM thalamocortical neurons, characterized by a switch from interictal, irregular, single-spike activity also applies to $\boldsymbol{A} \mathbf{1}$ and $\boldsymbol{A 2}$.
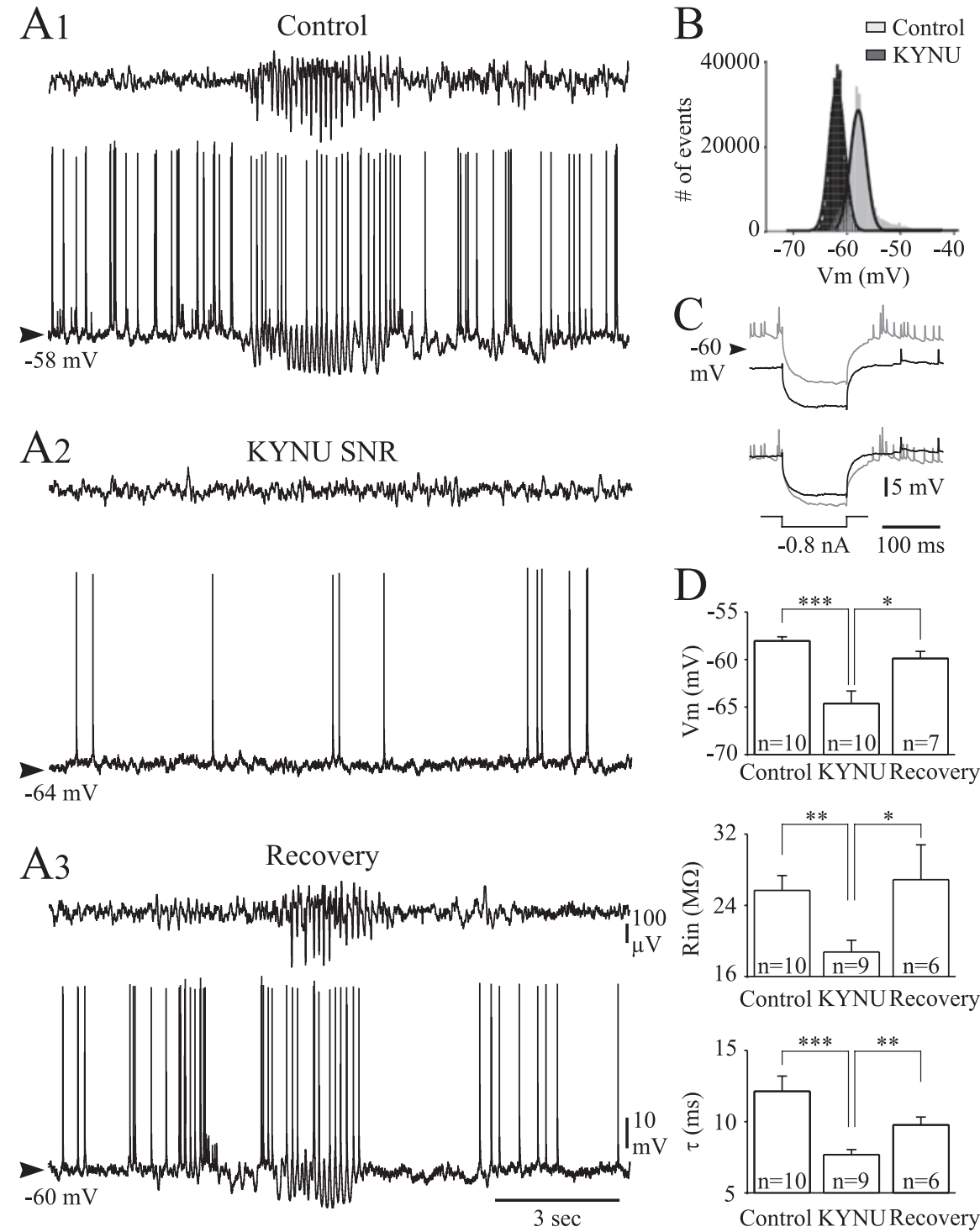

Figure 9. Intranigral injection of kynurenate abolishes SWDs and decreases cortical neurons excitability. $\boldsymbol{A}$, Simultaneous recording of the spontaneous intracellular activity (bottom traces) of an orofacial motor cortex neuron with the corresponding surface EEG (top trace), in control (A1), during kynurenate-induced SWD extinction (A2), and after SWD recovery (A3). Note that the transient blockade of ictal activity was associated in the recorded cortical cell with a decrease in the firing rate and a membrane hyperpolarization. $\boldsymbol{B}$, Distribution of the interictal membrane potential, from the same cortical neuron, in control (gray bars) and during the kynurenate-induced antiepileptic effect (black bars). The membrane potential in control was unimodally distributed around a mean value of $-57 \mathrm{mV}\left(n=2.5 \times 10^{5}\right.$ values; bin size, $0.5 \mathrm{mV}$; Gaussian fit, $\left.r^{2}=0.98\right)$ and shifted to more hyperpolarized values (mean, $-62 \mathrm{mV} ; n=2.5 \times 10^{5}$ values; bin size, $0.5 \mathrm{mV}$; Gaussian fit, $r^{2}=0.99$ ). C, Top, DC superimposition of averaged ( $n=10$ ) voltage responses (top traces) of the same cortical cell to intracellular injections of negative current pulse before (gray) and during (black) kynurenate-induced SWDs suppression. Bottom, The same voltage traces are graphically superimposed (bottom traces) by matching the membrane potential before the start of the pulse. Note the decrease in both apparent input resistance and time constant after drug application. $\boldsymbol{D}$, Pooled data showing that antiepileptic action of kynurenate intranigral injection was correlated in cortical neurons with significant $\left({ }^{* * *} p<0.001,{ }^{* *} p<0.01,{ }^{*} p<0.05\right)$ increase in membrane potential $\left(V_{\mathrm{m}}\right)$ and decrease in apparent membrane input resistance $\left(R_{\text {in }}\right)$ and time constant $(\tau)$. $\boldsymbol{A}-\boldsymbol{C}$ are from the same cell. The arrows at the left of the intracellular records indicate the mean interictal membrane potential. The calibration in $\mathbf{A} 3$

to burst firing in-phase with EEG spikes. During SWDs, the mean firing rate of VM thalamic cells was tripled with a firing probability in association with individual EEG spikes as high as $\sim 0.5$. This seizure-associated change in firing frequency and pattern contrasts with our observations in the present work from VL thalamic neurons (Fig. 6A1) and with the majority of specific thalamocortical neurons previously recorded during spike-and-wave activity in GAERS (Pinault et al., 1998; 
Charpier et al., 1999) and cats (Steriade and Contreras, 1995; Timofeev et al., 1998; Timofeev and Steriade, 2004). Indeed, these specific thalamocortical neurons show no bursting activity and their firing decreases during SWDs, likely because of a sustained inhibition arising from the reticular thalamic nucleus (Steriade and Contreras, 1995; Slaght et al., 2002a).

The end of the SWD in the EEG coincided with the cessation of VM thalamic intracellular oscillations and removal of the tonic hyperpolarization. The postictal membrane repolarization was typically followed by a short (0.2-3.5 s) and intense (4-20 action potentials) period of firing. This postictal rebound of excitation, which was not associated with a prominent synaptic depolarization (Fig. 5A1), could originate from a disinhibitory mechanism attributable to a decrease in the activity of nigrothalamic neurons at the end of cortical paroxysms (Deransart et al., 2003). However, we cannot exclude the contribution of a rebound response in corticothalamic neurons (Grenier et al., 1998; Timofeev et al., 2002) and/or of an intrinsic postinhibitory excitation attributable to $I_{\mathrm{h}}$ and/or $I_{\mathrm{T}}$. The increase in firing of $\mathrm{VM}$ thalamic neurons associated with the termination of the seizure, could be responsible for the postictal rebound of depolarization in striatal output neurons (Arbuthnott et al., 1990; Slaght et al., 2004), which, in turn, might contribute to the transient interruption of firing in SNR neurons at the end of cortical paroxysms (Deransart et al., 2003).

\section{Disinhibition of the thalamocortical pathway and decrease in cortical neurons excitability}

We showed that unilateral injection of a nonselective antagonist of glutamatergic receptors in the SNR transiently suppresses cortical SWDs concomitantly with an elevated but arrhythmic firing in VM thalamocortical neurons. This finding is consistent with previous work showing that bilateral blockade of glutamatergic transmission in the SNR has antiepileptic effects (Deransart et al., 1996). Moreover, it has been already shown that the pharmacological blockade of GABAergic nigrothalamic activity in normal rats causes a time-locked increase in the activity of VM thalamocortical cells through a process of disinhibition (Deniau and Chevalier, 1985; Chevalier and Deniau, 1990). This transition of activity in thalamic neurons, associated with the desynchronized interictal EEG, is also consistent with the thalamic tonic firing recorded during brain-activated states of waking, whereas rhythmic bursting (as seen during SWDs) is mainly present during unconsciousness-associated cortical slow waves (Glenn and Steriade, 1982; Llinas and Steriade, 2006).

The disinhibition of thalamocortical neurons, which resulted in a cessation of seizures, was associated with a decrease in cortical neurons excitability, expressed by a decrease in firing rate and a decrease in apparent membrane input resistance and time constant. The increase in membrane conductance, together with alteration in membrane time constant, might produce a shunting effect on depolarizing synaptic potentials, leading to a dramatic decrease in their amplitude and making their temporal summation less effective (Rall, 1977). Such a decrease in membrane excitability could account for the lack of large-amplitude synaptic depolarizations in cortical neurons, which might explain, together with the hyperpolarization, the decrease in cortical firing rate (Fig. 9A2).

The origin of the decreased excitability of cortical neurons after disinhibition of thalamocortical neurons remains unknown. However, it is plausible that the increased activity of nonspecific thalamocortical cells causes a widespread feedforward cortical inhibition by activating cortical GABAergic inter- neurons (Swadlow, 2003; Thomson and Bannister, 2003), resulting in an increase in the membrane conductance (Staley and Mody, 1992) of corticothalamic cells.

Basal ganglia as an on-line control system of absence seizures The possibility that absence seizures are controlled by the SNR first emerged from pharmacological studies in GAERS showing that a bilateral inhibition of SNR suppresses cortical SWDs (Depaulis et al., 1988, 1989; Deransart et al., 1996, 1998, 2001). Because the blockade of the GABAergic transmission at the level of the superior colliculus, which likely originates from the SNR, results in an alteration of generalized nonconvulsive seizures (Depaulis et al., 1990), it has been first postulated the involvement of the nigrotectal pathway. The present findings, showing that changes in the electrophysiological activity of VM thalamic cells are correlated with a cessation of SWDs, reinforce the "nigrothalamic" hypothesis and suggest that basal ganglia could control on-line absence seizures. During SWDs, VM thalamic neurons exhibited repetitive bursting activity generated, at least in part, by the nigrothalamic inhibition responsible for a deinactivation of $I_{\mathrm{T}}$. Consistent with the temporal relationships and the association strength we measured between cortical and thalamic activities (Fig. $5 B$ ) during the main body of SWDs, the rhythmic bursting in the thalamocortical loop should provide a resonant circuitry sustaining the cortical discharges and maintaining the coherence of seizure activity. The rebound of excitation of striatonigral neurons at seizure termination (Slaght et al., 2004) would be responsible for the decrease of firing in nigrothalamic neurons (Deransart et al., 2003). Thus, the subsequent tonic firing in VM thalamocortical neurons, through a disinhibitory process, might contribute to the cortical desynchronization (Glenn and Steriade, 1982) and, consequently, to the termination of the seizure and the recovery of conscious processes.

\section{References}

Arbuthnott GW, MacLeod NK, Maxwell DJ, Wright AK (1990) Distribution and synaptic contacts of the cortical terminals arising from neurons in the rat ventromedial thalamic nucleus. Neuroscience 38:47-60.

Bal T, von Krosigk M, McCormick DA (1995) Role of the ferret perigeniculate nucleus in the generation of synchronized oscillations in vitro. J Physiol (Lond) 483:665-685.

Bruno RM, Khatri V, Land PW, Simons DJ (2003) Thalamocortical angular tuning domains within individual barrels of rat somatosensory cortex. J Neurosci 23:9565-9574.

Charpier S, Lereshe N, Deniau J-M, Mahon S, Hughes SW, Crunelli V (1999) On the putative contribution of $\mathrm{GABA}_{\mathrm{B}}$ receptors to the electrical events occurring during spontaneous spike and waves discharges. Neuropharmacology 38:1699-1706.

Chevalier G, Deniau JM (1982) Inhibitory nigral influence on cerebellar evoked responses in the rat ventromedial thalamic nucleus. Exp Brain Res 48:369-376.

Chevalier G, Deniau JM (1990) Disinhibition as a basic process in the expression of striatal functions. Trends Neurosci 13:277-280.

Chevalier G, Vacher S, Deniau JM, Desban M (1985) Disinhibition as a basic process in the expression of striatal functions. I. The striatonigral influence on tecto-spinal/tecto-diencephalic neurons. Brain Res 334:215-226.

Crunelli V, Leresche N (2002) Childhood absence epilepsy: genes, channels, neurons and networks. Nat Rev Neurosci 3:371-382.

Danober L, Deransart C, Depaulis A, Vergnes M, Marescaux C (1998) Pathophysiological mechanisms of genetic absence epilepsy in the rat. Prog Neurobiol 55:27-57.

Deniau JM, Chevalier G (1985) Disinhibition as a basic process in the expression of striatal functions. II. The striato-nigral influence on thalamo- 
cortical cells of the ventromedial thalamic nucleus. Brain Res 334:227-233.

Deniau JM, Chevalier G (1992) The lamellar organization of the rat substantia nigra pars reticulata: distribution of projection neurons. Neuroscience 46:361-377.

Depaulis A, Vergnes M, Marescaux C, Lannes B, Warter J (1988) Evidence that activation of GABA receptors in the substantia nigra suppresses spontaneous spike-and-wave discharges in the rat. Brain Res 448:20-29.

Depaulis A, Snead OI, Marescaux C, Vergnes M (1989) Suppressive effects of intranigral injection of muscimol in three models of generalized non-convulsive epilepsy induced by chemical agents. Brain Res 498:64-72.

Depaulis A, Liu Z, Vergnes M, Marescaux C, Micheletti G, Warter JM (1990) Suppression of spontaneous generalized non-convulsive seizures in the rat by microinjection of GABA antagonists into the superior colliculus. Epilepsy Res 5:192-198.

Deransart C, Depaulis A (2002) The control of seizures by the basal ganglia? A review of experimental data. Epileptic Disord 4 [Suppl 3]:S61-S72.

Deransart C, Marescaux C, Depaulis A (1996) Involvement of nigral glutamatergic inputs in the control of seizures in a genetic model of absence epilepsy in the rat. Neuroscience 71:721-728.

Deransart C, Vercueil L, Marescaux C, Depaulis A (1998) The role of basal ganglia in the control of generalized absence seizures. Epilepsy Res 32:213-223.

Deransart C, Le-Pham BT, Hirsch E, Marescaux C, Depaulis A (2001) Inhibition of the substantia nigra suppresses absences and clonic seizures in audiogenic rats, but not tonic seizures: evidence for seizure specificity of the nigral control. Neuroscience 105:203-211.

Deransart C, Hellwig B, Heupel-Reuter M, Leger JF, Heck D, Lucking (2003) Single-unit analysis of substantia nigra pars reticulata neurons in freely behaving rats with genetic absence epilepsy. Epilepsia 44:1513-1520.

Destexhe A, Sejnowski TJ (2001) Thalamocortical assemblies: how ion channels, single neurons and large scale networks organise sleep oscillations. Oxford: Oxford UP.

Di Chiara G, Porceddu ML, Morelli M, Mulas ML, Gessa GL (1979) Evidence for a GABAergic projection from the substantia nigra to the ventromedial thalamus and to the superior colliculus of the rat. Brain Res 176:273-284.

Glenn LL, Hada J, Roy JP, Deschenes M, Steriade M (1982) Anterograde tracer and field potential analysis of the neocortical layer I projection from nucleus ventralis medialis of the thalamus in cat. Neuroscience 7:1861-1877.

Grenier F, Timofeev I, Steriade M (1998) Leading role of thalamic over cortical neurons during postinhibitory rebound excitation. Proc Natl Acad Sci USA 95:13929-13934.

Hall RD, Lindholm EP (1974) Organization of motor and somatosensory neocortex in the albino rat. Brain Res 66:23-28.

Herkenham M (1979) The afferent and efferent connections of the ventromedial thalamic nucleus in the rat. J Comp Neurol 183:487-518.

Herkenham M (1980) Laminar organization of thalamic projections to the rat neocortex. Science 207:532-535.

Kilpatrick JC, Starr MS, Fletcher A, James TA, MacLeod NK (1980) Evidence for a GABAergic nigrothalamic pathway in the rat. I. Behavioural and biochemical studies. Exp Brain Res 40:45-54.

Llinas R, Jahnsen H (1982) Electrophysiology of mammalian thalamic neurones in vitro. Nature 297:406-408.

Llinas R, Steriade M (2006) Bursting of thalamic neurons and states of vigilance. J Neurophysiol 95:3297-3308.

Lopes da Silva F, Pijn JP, Boeijinga P (1989) Interdependence of EEG signals: linear vs. nonlinear associations and the significance of time delays and phase shifts. Brain Topogr 2:9-18.

Mahon S, Casassus G, Mulle C, Charpier S (2003) Spike-dependent intrinsic plasticity increases firing probability in rat striatal neurons in vivo. J Physiol (Lond) 550:947-959.

Mailly P, Charpier S, Menetrey A, Deniau JM (2003) Three-dimensional organization of the recurrent axon collateral network of the substantia nigra pars reticulata neurons in the rat. J Neurosci 23:5247-5257.

Marescaux C, Vergnes M, Depaulis A (1992) Genetic absence epilepsy in rats from Strasbourg—a review. J Neural Transm Suppl 35:37-69.
McCormick DA, Pape HC (1990) Properties of a hyperpolarizationactivated cation current and its role in rhythmic oscillation in thalamic relay neurones. J Physiol (Lond) 431:291-318.

Meeren HK, Pijn JP, Van Luijtelaar EL, Coenen AM, Lopes da Silva FH (2002) Cortical focus drives widespread corticothalamic networks during spontaneous absence seizures in rats. J Neurosci 22:1480-1495.

Moran A, Avendano C, Reinoso-Suarez F (1982) Thalamic afferents to the motor cortex in the cat. A horseradish peroxidase study. Neurosci Lett 33:229-233.

Myers RD (1971) Methods for chemical stimulation of the brain. In: Methods of psychobiology, Vol 1 (Myers RD, ed), pp 247-280. New York: Academic.

Neafsey EJ, Bold EL, Hass G, Hurley-Gius KM, Quirk G, Sievert CF, Terreberry RR (1986) The organization of the rat motor cortex: a microstimulation mapping study. Brain Res 396:77-96.

Panayiotopoulos CP (1997) Absences epilepsies. In: Epilepsy: a comprehensive textbook (Engel Jr J, Pedley TA, eds), pp 2327-2346. Philadelphia: Lippincott-Raven.

Paxinos G, Watson C (1986) The rat brain in stereotaxic coordinates, Ed 2. London: Academic.

Paz JT, Deniau JM, Charpier S (2005a) Rhythmic bursting in the corticosubthalamo-pallidal network during spontaneous genetically determined spike and wave discharges. J Neurosci 25:2092-2101.

Paz JT, Polack PO, Slaght SJ, Deniau JM, Charpier S (2005b) Propagation of cortical paroxysms in basal ganglia circuits during absence seizures. In: The basal ganglia VIII (Bolam JP, Ingham CA, Magill PJ, eds), pp 55-65. New York: Springer.

Pinault D (1996) A novel single-cell staining procedure performed in vivo under electrophysiological control: morpho-functional features of juxtacellularly labeled thalamic cells and other central neurons with biocytin or Neurobiotin. J Neurosci Methods 65:113-136.

Pinault D (2003) Cellular interactions in the rat somatosensory thalamocortical system during normal and epileptic 5-9 Hz oscillations. J Physiol (Lond) 552:881-905.

Pinault D, Lereshe N, Charpier S, Deniau JM, Marescaux C, Vergnes M, Crunelli V (1998) Intracellular recordings in thalamic neurones during spike and waves discharges in rats with absence epilepsy. J Physiol (Lond) 509:449-456.

Rall W (1969) Time constants and electrotonic length of membrane cylinders and neurons. Biophys J 9:1483-1508.

Rall W (1977) Core conductor theory and cable properties of neurons. In: Handbook of physiology, the nervous system, Vol 1, Cellular biology of neurons (Kandell ER, Brookhart JM, Mountcastle VB, eds), pp 39-97. Bethesda, MD: American Physiological Society.

Robledo P, Feger J (1990) Excitatory influence of rat subthalamic nucleus to substantia nigra pars reticulata and the pallidal complex: electrophysiological data. Brain Res 518:47-54.

Simons DJ, Carvell GE (1989) Thalamocortical response transformation in the rat vibrissa/barrel system. J Neurophysiol 61:311-330.

Slaght SJ, Leresche N, Deniau JM, Crunelli V, Charpier S (2002a) Activity of thalamic reticular neurons during spontaneous genetically determined spike and wave discharges. J Neurosci 22:2323-2334.

Slaght SJ, Paz T, Mahon S, Maurice N, Charpier S, Deniau JM (2002b) Functional organization of the circuits connecting the cerebral cortex and the basal ganglia: implications for the role of the basal ganglia in epilepsy. Epileptic Disord 4 [Suppl 3]:S9-S22.

Slaght SJ, Paz T, Chavez M, Deniau JM, Mahon S, Charpier S (2004) On the activity of the corticostriatal networks during spike-and-wave discharges in a genetic model of absence epilepsy. J Neurosci 24:6816-6825.

Smith Y, Parent A (1988) Neurons of the subthalamic nucleus in primates display glutamate but not GABA immunoreactivity. Brain Res 453:353-356.

Staley KJ, Mody I (1992) Shunting of excitatory input to dentate gyrus granule cells by a depolarizing GABAA receptor-mediated postsynaptic conductance. J Neurophysiol 68:197-212.

Steriade M, Contreras D (1995) Relations between cortical and thalamic cellular events during transition from sleep patterns to paroxysmal activity. J Neurosci 15:623-642.

Steriade M, Jones EG, Llinas RR (1990) Intrinsic properties and ionic conductances of thalamic cells. In: Thalamic oscillations and signaling (Ste- 
riade $\mathrm{M}$, Jones EG, Llinas RR, eds), pp 115-125. New York: Wiley Interscience.

Stone TW (1993) Neuropharmacology of quinolinic and kynurenic acids. Neuropharmacology 45:309-379.

Swadlow HA (2003) Fast-spike interneurons and feedforward inhibition in awake sensory neocortex. Cereb Cortex 13:25-32.

Thomson AM, Bannister AP (2003) Interlaminar connections in the neocortex. Cereb Cortex 13:5-14.

Timofeev I, Steriade M (2004) Neocortical seizures: initiation, development and cessation. Neuroscience 123:299-336.

Timofeev I, Grenier F, Steriade M (1998) Spike-wave complexes and fast components of cortically generated seizures. IV. Paroxysmal fast runs in cortical and thalamic neurons. J Neurophysiol 80:1495-1513.

Timofeev I, Bazhenov M, Sejnowski T, Steriade M (2002) Cortical hyperpolarization-activated depolarizing current takes part in the generation of focal paroxysmal activities. Proc Natl Acad Sci USA 99:9533-9537.

Ueki A (1983) The mode of nigro-thalamic transmission investigated with intracellular recording in the cat. Exp Brain Res 49:116-124.

Williams D (1953) A study of thalamic and cortical rhythms in petit mal. Brain 76:56-69.

Yamamoto T, Noda T, Samejima A, Oka H (1985) A morphological investigation of thalamic neurons by intracellular HRP staining in cats. J Comp Neurol 236:331-347.

Yoshida M, Omata S (1979) Blocking by picrotoxin of nigra-evoked inhibition of neurons of ventromedial nucleus of the thalamus. Experientia 35:794.

Zilles K (1985) The cortex of the rat: a stereotaxic atlas. Berlin: Springer. 